\title{
Portable single-pan wood stoves of high efficiency for domestic use
}

\author{
H S MUKUNDA, U SHRINIVASA and S DASAPPA
}

Centre for the Application of Science and Technology to Rural Areas (ASTRA), Indian Institute of Science, Bangalore 560 012, India

MS received 5 August 1987; revised 26 December 1988

\begin{abstract}
We describe and evaluate here certain new designs for singlepan wood stoves of high efficiency. The novelty in the design consists chiefly in the use of improved geometries for the combustion chamber and the vessel support. Extensive tests on water boiling and cooking demonstrate efficiencies exceeding $40 \%$; these high values are attributable to stove operation at near stoichiometric conditions. The configuration termed Swosthee is among the most efficient stoves available to date, and is able to burn wet wood under partial loading with little accompanying smoke. Two versions of the same basic design provide inexpensive stoves that retain to a large extent the advantages of the original design like the generation of pollutants at low levels in the flue gases and the ability to handle wet wood.

For the proposed designs the dependence of their cooking efficiency on vessel size has been obtained. These are reflected in terms of specific fuel consumption (whose variation is a function of vessel size). The present designs, when compared to other currently available improved stove designs like Priyagni, Tara, the Tamil Nadu Stove and the ASTRA three-pan stove, are better with respect to at least one of the following criteria-efficiency, cost, $\mathrm{CO}$ emission and portability. The stoves are presently being disseminated in small numbers.
\end{abstract}

Keywords. Wood stoves; portable stoves; metal stoves; single-pan stoves; high efficiency; water boiling efficiency; specific fuel consumption; emissions; improved combustion; economics.

\section{Introduction}

Conservation of both renewable and nonrenewable sources of energy has become the major criterion for the choice of technology today, and any further elaboration on the theme would be superfluous. However, effective achievement of conservation in any technology is gauged chiefly by the extent to which systems based on it could be made economical enough to find wide use and acceptability. One such area in which conservation is important is the use of wood as fuel in stoves and this requires the development of inexpensive and fuel efficient stove designs. 
Surprisingly, in India a strong motivation for the development of portable singlepan wood stoves arises from a different consideration, not often recognised. In urban areas energy needs for domestic cooking are mostly met by electricity, liquid petroleum gas (LPG) or kerosene. Dependence on any one, two or all the three does not always ensure an uninterrupted supply of energy for cooking. Due to the wide gap between demand and supply, breaks in supply of electricity and low supply voltages (65-75\% of the normal) are not uncommon for several months in a year. Bottled gas (LPG) gets to the users through surface transportation, a system which quite often causes several days delay in delivery time. The supply of kerosene is also similarly affected. Hence it is not uncommon for a housewife to run out of all the three sources. Under the circumstances, she could benefit from a 'stand by' device which can burn any easily available biomass efficiently. Therefore we expect a large and ready urban market for compact and portable wood stoves. Since the urban market is likely to be relatively easier to penetrate because of its better organisation, easy access to large educated groups and relatively large money resources for buying new stoves, it promises to be advantageous to develop new designs, to begin with, for the urban users. It is particularly important because some circles have expressed a fear that penetration of new stoves to significant levels might take several decades (Krishna Prasad 1985a). On the other hand, in rural areas, whose fuel resources are well investigated, it is recognised that a wood stove is an essential component in most houses and the majority of traditional stoves are inefficient (Bhatt 1982; Geller 1982; Gupta et al 1982; Gill 1983; Bussmann 1984; ASTRA 1987a; the last reference mentions obtaining a water-boiling efficiency of $15.7 \pm 3.7 \%$ on traditional stoves in the Ungra area). Hence there is a need for efficient wood stoves in both urban and rural areas. "However, heat and mass transfer processes as well as the fluid dynamics within even the simplest wood burning stoves are extremely complicated... As mentioned by Verhaart (1981) engineering considerations (complex in themselves) interrelate with economic, social and ecological factors, making the design of acceptable and efficient stoves extremely complex" (Zaror \& Pyle 1982).

The rest of this report examines the current status of the work on wood stoves available in many reports (De Lepeleire et al 1981; Clans \& Sulilatu 1983; Krishna Prasad \& Verhaart 1983; Krishna Prasad \& Sangen 1983; Lokras et al 1983; Krishna Prasad 1985a; Krishna Prasad et al 1985; Krist-Spit \& Van der Heeden 1985; Baldwin 1986; Bussman 1988) and arrives at a set of specifications for a new design followed by a discussion on the stoves developed by the authors.

\section{The scenario}

\subsection{LPG and kerosene stoves}

Many households in cities have LPG stoves. Normally these are provided with two burners of 1 and $2 \mathrm{~kW}$ maximum capacity respectively. Quoting from Segeler (1966), Krishna Prasad (1985b) reports that they operate at efficiencies of about $40-60 \%$. Wick-type kerosene stoves aiso are normally of 1 and $2 \mathrm{~kW}$ capacity (with 8-10 and 16 wicks, respectively). The better ones amongst a few models tested by us operated at efficiencies of $45-55 \%$ under reasonable wind conditions and $48-58 \%$ 
under low wind conditions as observed in the laboratory (Bussman 1988 has obtained similar effects from wind on wood stoves). Krishna Prasad et al (1983) have done extensive testing in their laboratory on 11 numbers of wick-type kerosene stoves, 5 pressure-fed ones and 3 gas stoves and have obtained efficiencies of 24 to $48 \%$ for wick stoves, $49-56 \%$ for pressure-fed stoves and 58 to $61 \%$ for gas stoves. The wide dispersion in the efficiency values could have been due to the vessel size, the power at which the burner is operated, the type of stove used and its age. Amongst the stoves tested by us, those with slightly higher efficiencies had shields around the flame, apart from the perforated cylindrical shrouds around the burner. One of the factors that we feel is often completely overlooked in efficiency statements on wick-type kerosene stoves is that their operating efficiencies drop during usage due to wicks getting fouled due to spillages from cooking vessels. In addition, uneven relative heights of wicks above metallic supports cause nonoptimal operation of the burner which, at times, could be accompanied by significant sooting and acrid smoke, a feature usually aggravated by fouled-up wicks.

\subsection{Available wood stove designs}

A variety of wood stoves of single, two and three pans have been designed, built and tested both in India and abroad. Krishna Prasad et al (1985) and Baldwin (1986) list most of the relevant publications. Single-pan stoves are often made of metal, while two- and three-pan stoves are usually of mud and mortar. Most twoand three-pan stoves need a chimney to create a draft and also to help in eliminating smoke in the kitchen. The best efficiency of commercially available single-pan stoves that we came across in India has been $30 \%$ as reported in the Rapa Bulletin (1986) and $34 \%$ as measured by us under low wind conditions. The efficiency could be expected to drop by several per cent due to wind (see Bussman 1988).

A survey of tests on a number of stove designs is available in Krishna Prasad \& Sangen (1983). Figure 1 is taken from this reference. As can be noticed from the figure, all stoves excepting the "shielded fire" and the "experimental stove" have efficiencies of less than $30 \%$. The performance of the "high efficiency" stove or the so-called "shielded fire" stove is discussed in detail in many publications of the wood stove group of the Eindhoven University of Technology, and the experience of the group is summarised in Krishna Prasad et al (1985) and Bussman (1988). In this stove and in its variations called the "experimental stove" and the "Tamil Nadu Stove" the convective heat transfer between the hot gases and the vessel is enhanced by keeping the distance between the walls of the vessel and the chamber enveloping the vessel small. The gap is as small as a few millimetres and its performance was found to be sensitive to the spacing. Their rated power is high. For example, the "Tamil Nadu Stove" operates between 3.6 to $13 \mathrm{~kW}$ based on the input power. These stoves are slightly to moderately complex for fabrication and are also expensive, made of aluminium and steel, and weighing $28 \mathrm{~kg}$ and therefore would cost at least Rs 600 to make as estimated by us. Since their rated powers are far larger than the desired power range for cooking (based on the rated power of available gas stoves, the range is about 0.6 to $1.2 \mathrm{~kW}$ in terms of heat transferred to the vessel), it would be difficult to scale them down because of limitations on 


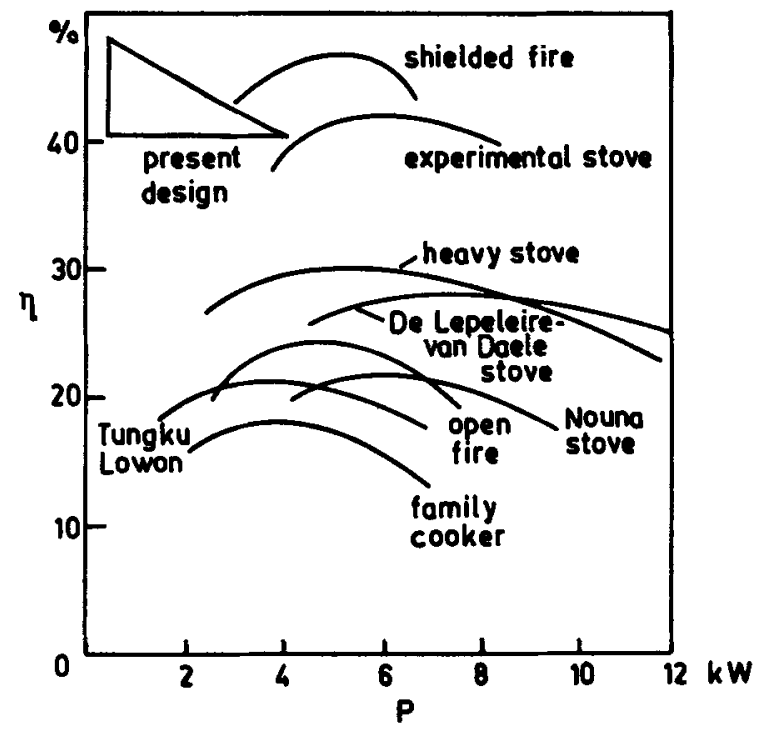

Figure 1. Efficiencies $(\eta)$ of available stove designs and how they vary with operating power (P) (Krishna Prasad \& Sangen 1983).

minimum gap which can be used in practice (see Baldwin 1986, for a discussion). Thus as far as the authors' knowledge goes, despite many claims on the signs of success of wood burning cook-stoves (Baldwin et al 1985), there is not even a single commercially available versatile single-pan wood stove in India with efficiencies approaching that of kerosene stoves.

Most of the stoves use primary and secondary air inlets for obtaining good combustion, in spite of which single-pan stoves without chimneys have the problem of smoke (Krishna Prasad \& Sangen 1983).

\subsection{Three-pan stoves}

Three-pan stoves have been investigated and several built by many organisations both in India and abroad (Krishna Prasad \& Sangen 1983). The best of them in terms of efficiency and specific fuel consumption (SFC, $\mathrm{kg}$ of wood required to cook $1 \mathrm{~kg}$ of food), according to Krishna Prasad (1985), is the "ASTRA-Ole" developed at the Indian Institute of Science, Bangalore; it has an efficiency of $40-45 \%$ in the laboratory and $35 \pm 6 \%$ under field conditions (see ASTRA 1987a and Lokras et al 1983). The two-pan "Nouna" stove in its modified version has a measured efficiency of $35 \pm 3 \%$ (Van der Heeden et al 1983). Both the designs utilise chimneys to create the necessary draft and the flue gas passage dimensions are adjusted to enhance convective heat transfer. The heat extracted in the first pan amounts to about $20 \%$, in the second to $15 \%$ and in the third to $10 \%$. In two-pan stoves, the first-pan efficiency amounts to about $25 \%$ and the second to $12 \%$. Thus an equivalent single-pan stove of the same design may be assumed to have about $25 \%$ efficiency. This is also consistent with the observation that single-pan stoves without chimneys seem to have efficiencies not exceeding $25 \pm 5 \%$ (see Bussman 1984, for many field measurements).

There are significant differences in efficiencies measured under field and laboratory conditions in the case of the ASTRA-Ole, which have been traced by 
Shailaja \& Ravindranath (1985) to the way most stoves are propagated. A large number of masons trained by a batch of teacher-masons, who have themselves been trained by ASTRA (Centre for the Application of Science and Technology to Rural Areas, Indian Institute of Science, Bangalore, India), construct these stoves (see also ASTRA 1987a). Because of (i) the hierarchy in the training process, (ii) the average skills of the personnel actually involved in the construction, and (iii) the decision often made by the local authorities to use substitutes for the materials not precisely specified by the designers, the final version of the stove differs from the one intended (a detailed field evaluation is available in ASTRA 1987a,b). Since the design optimises the convective heat transfer, the passage dimensions are critical. Once these are altered even slightly, the efficiency can be expected to drop. This fear is also expressed in Baldwin (1986). Micuta (1985) describes "to skilled technicians" a number of "general drawings .... for building stove models which they will then test and adapt to local conditions". "Technicians are warned that their first attempts will rarely prove satisfactory for whilst the concepts of the stoves presented" by him "are relatively simple, a certain amourit of practice and experience is required to master their construction and use". However this experience is contradictory to the opinion expressed in Anon (1984) which states that "... scientists have demonstrated that when traditional (three-stone) cooking is done carefully, efficiencies are equal to those of well-designed Chula or Lorena stoves. There is little doubt that the poor who suffer firewood shortages use their supplies with care". See Foley \& Moss (1983) and Manibog (1984) for further critical appraisals of stove programmes all over the world.

\subsection{A survey of users}

About 0.15 million ASTRA-Ole's exist today. A survey of its users conducted by ASTRA (1987b) has indicated that it is immensely popular because of its smokelessness and shortened cooking time. The high efficiency aspect which reduces the fuel consumption is noticeable only over large periods of time and is given secondary importance (Shailaja \& Ravindranath 1985). A complaint against the stove is that it occupies considerable space in the kitchen. This stove is therefore meant mostly for reasonably large-sized kitchens in rural areas. Many users have indicated the need for a two-pan stove and a portable single-pan stove. Apparently portability is very important in some areas of the country where cooking is a social event and there is often a need to shift the stove to suit the user's convenience.

\subsection{Single-pan stoves}

Single-pan stoves of the "Tamil Nadu design" type with their high efficiency of $47-50 \%$ are intended for fixed pan size. They are also of relatively high rated power as noted earlier.

Of late, two single-pan metal stoves, called Priyagni and Tara, are being marketed in India. Priyagni has been designed at the Central Power Research Institute, Bangalore (Rapa Bulletin 1986) and Tara by a private industry in New Delhi. They are shown in figure 2 and are essentially of the open-fire-combustion-ongrate type, with a shield in the case of Tara. Priyagni is stated to have a single point operating efficiency of $30 \%$ (Rapa Bulletin 1986) and Tara is expected to be of 

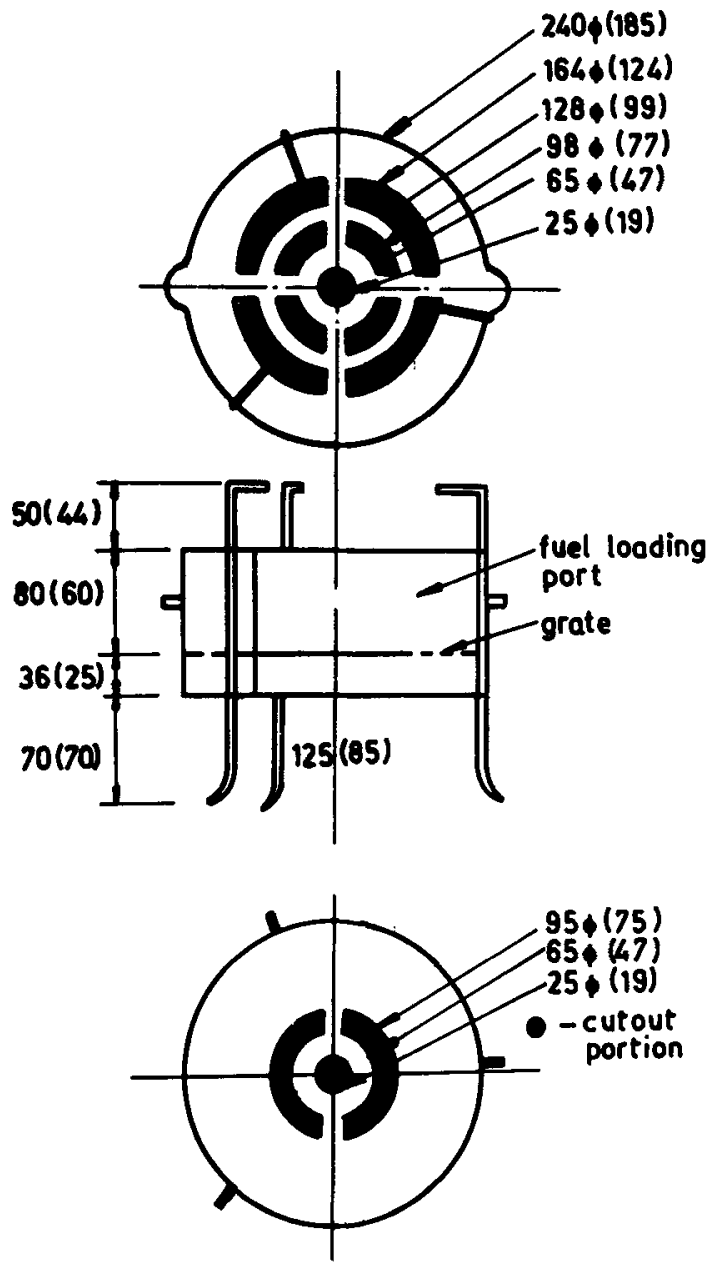

Figure 2a. Details of Priyagni-small (P-S) and Priyagni-medium (P-M); all dimensions are in millimetres in this and subsequent figures. Numbers in the brackets belong to P-S.

comparable efficiency. A comparison of the performance of these stoves with the present authors' designs is given in $\$ 11$.

Priyagni is marketed by the Orissa Rural Energy Development Agency (OREDA) under a central government subsidy scheme and about fifteen thousand of them have been introduced in rural Orissa (private communication, OREDA). There are claims about reduction in fuel consumption which are possibly true but the extent of benefits derived has not been evaluated as yet.

Tara is a stove which is being introduced in some Northern parts of India and there is no documentation available to the present authors on its diffusion or performance.

\subsection{Combustion and sooting}

All stoves designed so far use to a large extent the diffusive flame between air and fuel for combustion and to transfer heat directly to the vessel. Because the cold 

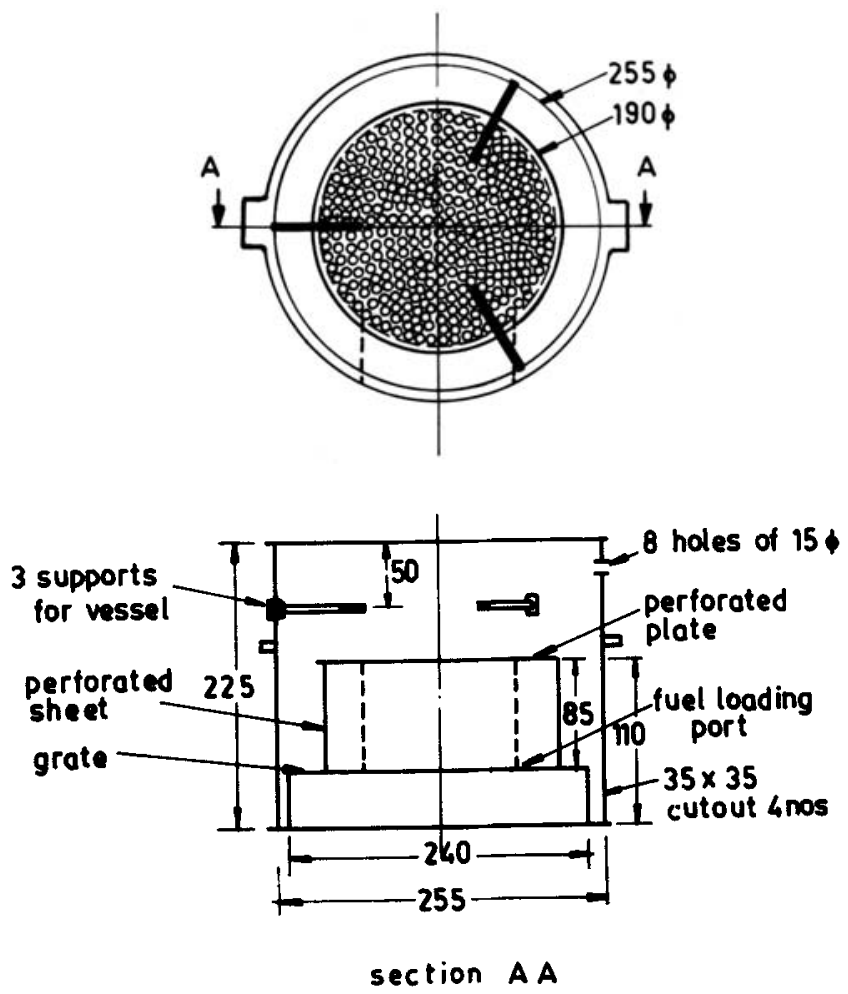

Figure 2b. Details of Tara (T-2).

surface is close to the flame, sooting of the vessel is expected to be significant, as is noticed with all current designs.

\section{Specifications for a new stove}

Specifications for a new stove are derived from an analysis of the earlier work and the authors' own experience with stoves; they are as follows:

(a) Power level : Stoves capable of transferring 0.6 to $2 \mathrm{~kW}$ to the pot are most suitable.

(b) Efficiency : As high as possible-the target being that of kerosene stoves $-45-50 \%$ considered reasonable.

(c) Smoke : Smokelessness is most essential.

(d) Soot : Sootless operation is desirable.

(e) Operation : Power level should be capable of being controlled between high heat and low heat for simmering.

(f) size

: As small as possible. A reference size would be that of the kerosene stove of comparable power (typical: $1 \mathrm{~kW}$ stove (based on fuel input) $-0.2 \mathrm{~m}$ dia and $0.25 \mathrm{~m}$ height; $2 \mathrm{~kW}$ stove $-0.25 \mathrm{~m}$ diameter and $0.3 \mathrm{~m}$ height).

(g) Price

: As low as possible; about Rs. 50 to Rs. 100 as in the case of kerosene stoves. 
(h) Convenience to : Should be user friendly in the best interpretation of the term. users Should be capable of being used with vessels of different sizes.

The last point, concerning the use with different sized vessels is particularly important because vessel size depends on the kind of food being cooked and also on individual and regional preferences. Though designing a stove of high efficiency for fixed vessel shape may be simpler, it is meaningful only in a few cases, like bathwater stoves, and is otherwise impractical. Thus, achieving high efficiency with a single-pan stove, without producing smoke or soot, without limiting its use to any particular vessel size and with provision to control the power level as required, are the authors' specifications for stoves.

\section{Rationale for design}

\subsection{Concepts involved}

Details about how to design wood stoves, available theoretical models and experimental data are summarised in Krishna Prasad et al (1985). More details are available in Bussman et al (1983) and De Lepeleire \& Christiaens (1983). Despite the above Emmons \& Athreya (1982) have the following to say: "The current scientific understanding of 'wood combustion' is not mature enough to provide a reliable quantitative prediction ... The final design of a stove should be determined experimentally". Therefore for about one and a half years during 1984-85, many attempts were made by us to meet the specifications listed earlier; three concepts were attempted, a dozen configurations were built and tested. Concepts tried out were (i) pyrolysis of wood/biomass in a chamber and burning the products with air, (ii) combustion of the fuel to produce hot cinders, allowing atmospheric air and the pyrolysis products to pass through hot cinders to produce some $\mathrm{CO}$ and $\mathrm{H}_{2}$ and burning this mixture with air at the top of the stove, and (iii) combustion of the fuel in a chamber with swirling air.

Verhaart (1982) gives tutorial sketches of the first two concepts, though no details of any prototypes attempted are available. However the authors got a few models built and tested. The first concept was successful in obtaining good combustion on the average, but hardly any control was possible. In fact it was found that loading the chamber with more fuel than can be consumed at the required rate causes a sudden release of pyrolysis gases, which tend to make the combustion fuel-rich, causing sooting and smoke, and resulting in large heating rates. Thus it was apparent that without a fuel-feeding device there was no possibility of varying the heating rate, particularly of lowering it when needed for simmering. Since this control is an important requirement, the design was abandoned.

The second concept, also taken from wood gasifier designs, did not quite succeed since there were problems of uneven power during the operation.

The third concept was implemented in a few designs and one of them led to a usable version (which we denote by the code S-1 during further discussion; see table 1 for details of symbols used to represent different stove models). Elements of this design are (1) a vertically arranged duct to carry hot gases and to create the necessary draft, (2) a combustion chamber below, and (3) a loading tegion, there 
Table 1. Notations for different stoves.

\begin{tabular}{ll}
\hline Stove & \\
\hline S-1 (I) & $1 \mathrm{~kW}$ Swosthee with tangential air inlet of $0.015 \times 0.07 \mathrm{~m}^{2}$ \\
S-1 (II) & $1 \mathrm{~kW}$ Swosthee with tangential air inlet of $0.015 \times 0.075 \mathrm{~m}^{2}$ \\
S-1 (III) & $1 \mathrm{~kW}$ Swosthee with tangenti 1 air inlet and a flat plate at the stove top to \\
& support the vessel \\
S-1 (M) & Modified S-1 (I) for reducing fabrication cost \\
S-2 & 2 kW Swosthee \\
MS-1.5 & Modified Swosthee of 1.5 kW nominal rating \\
MS-4.0 & Modified Swosthee of 4.0 kW nominal rating \\
P-S & Priyagni : small, to cook for 4-5 persons (Rapa Bulletin 1986) \\
P-M & Priyagni : medium, to cook for 7-8 persons (Rapa Bulletin 1986) \\
T-2 & Tara (private communication, Development Alternatives, New Delhi) \\
Tamil Nadu & Single-pan stove (Sulilatu \& Krist-Spit 1985) \\
ASTRA-Ole & 3-Pan ASTRA stove (Lokras et al 1983) \\
Shielded fire & Single-pan stove (Krishna Prasad \& Sangen 1983; Krishna Prasad et al 1985; \\
Experimental & Bussman 1988) \\
Nouna & Single-pan stove (Krishna Prasad \& Sangen 1983; Krishna Prasad et al 1985) \\
Amar & 2-Pan stove (Krishna Prasad \& Sangen 1983) \\
\hline
\end{tabular}

being no separate chimney. The vertical duct carrying combustion products provides the draft for air to be taken in at the sides in the lower region of the stove. The air is drawn in along a tangential direction providing for a longer residence time inside the chamber. Hot gases are taken out along the vertical duct which has provision for creating recirculation of gases inside it such that combustion can be completed within the height provided for the duct. The release of hot gases in an opening of small cross-section was expected to improve the efficiency as in gas stoves.

In order to ensure that the heat retained in the body of the stove is small, the entire stove is made from thin sheet metal. Further, to reduce heat losses to the ambient, the stove is covered with low density insulation of alumino silicates on the entire outer surface. When field tests were being conducted after completing the development, factors contributing to the high efficiency were reviewed. We found that the temperature of the gases transferring heat to the vessel plays a critical role. While premixing without adequate control on mixture ratio may keep the average temperature lower than the optimum and the efficiency may fall, high efficiency may still be obtained if the combustion is diffusion-dominant and the flame transfers most of the heat to the vessel. The only problem with the second mode is higher levels of soot and smoke. Thus, one is led to two different designs, both capable of high efficiency but producing different pollutant levels in the flue gases. The designs based on premixing are christened swOSTHEE-single-pan wood stoves of high efficiency (Mukunda \& Shrinivasa 1985; S-1 and S-2 refer to this design with rated power, based on fuel consumption rate, of 1 and $2 \mathrm{~kW}$ respectively). The models based on diffusion-dominated combustion as discussed above are called Modified 
Swosthee and are denoted by MS-1.5 and MS-4 for 1.5 and $4 \mathrm{~kW}$ ratings respectively (Mukunda et al 1986). See table 1 for details.

\subsection{The $1 \mathrm{~kW}$ stove}

Figure 3 shows the development version of the $1 \mathrm{~kW}$ stove, S-1. It weighs $1.5 \mathrm{~kg}$ without insulation, and $3.0 \mathrm{~kg}$ with insulation and an external cover. The fuel is loaded through a $0.03 \mathrm{~m} \times 0.03 \mathrm{~m}$ opening. The average combustion rate is $42 \times 10^{-6} \mathrm{~kg} / \mathrm{s}(0.15 \mathrm{~kg} / \mathrm{h})$ and the amount of fuel that needs to be charged at a time is two or three pieces of wood of 0.01 to $0.012 \mathrm{~m}$ diameter on an average.

The various dimensions of the stove have been chosen after considerable experimentation with several combinations. For instance, an increase in the size of the air inlet from $0.07 \mathrm{~m} \times 0.015 \mathrm{~m}$ to $0.07 \mathrm{~m} \times 0.020 \mathrm{~m}$ causes occasional back flow of gases indicating that flow circuit resistances are not favourable. Increasing the bottom

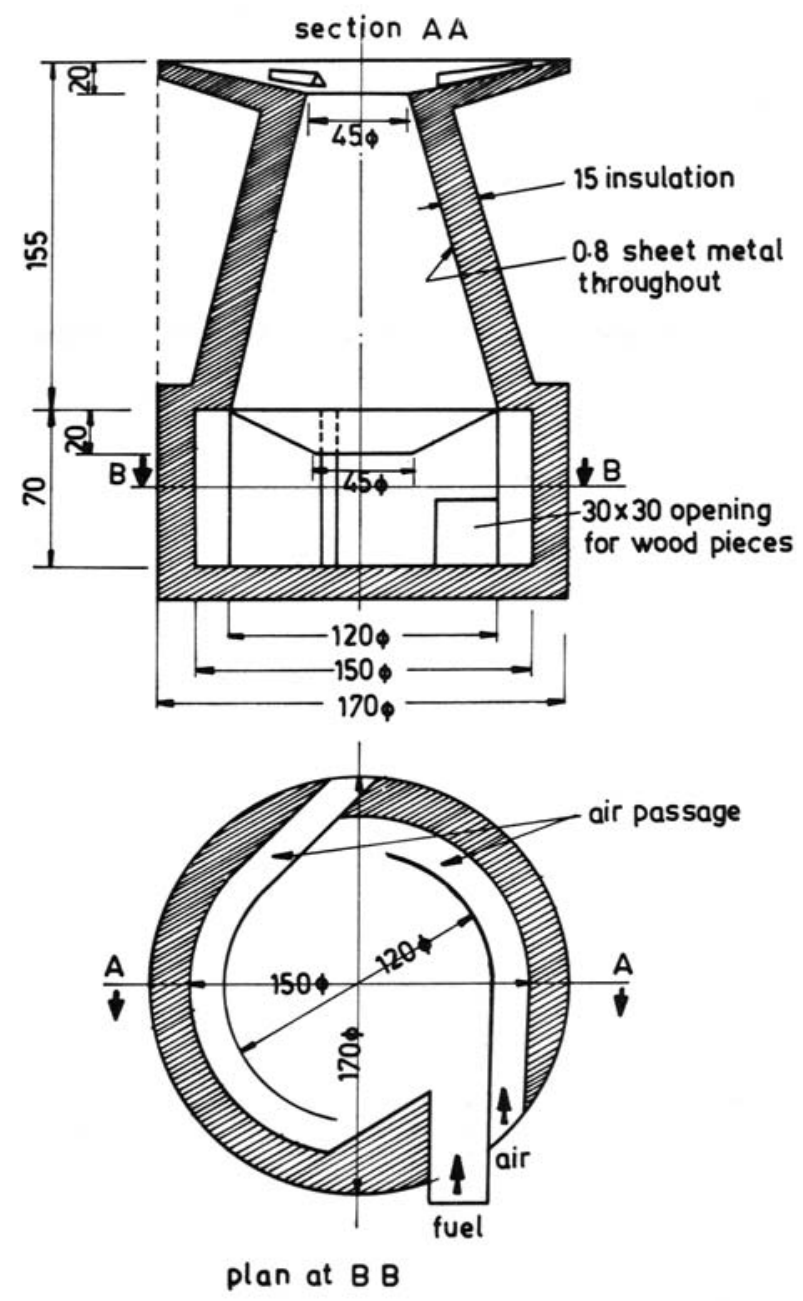

Figure 3a. Swosthee $1 \mathrm{~kW}-\mathrm{S}-1$ (I)-First prototype. 


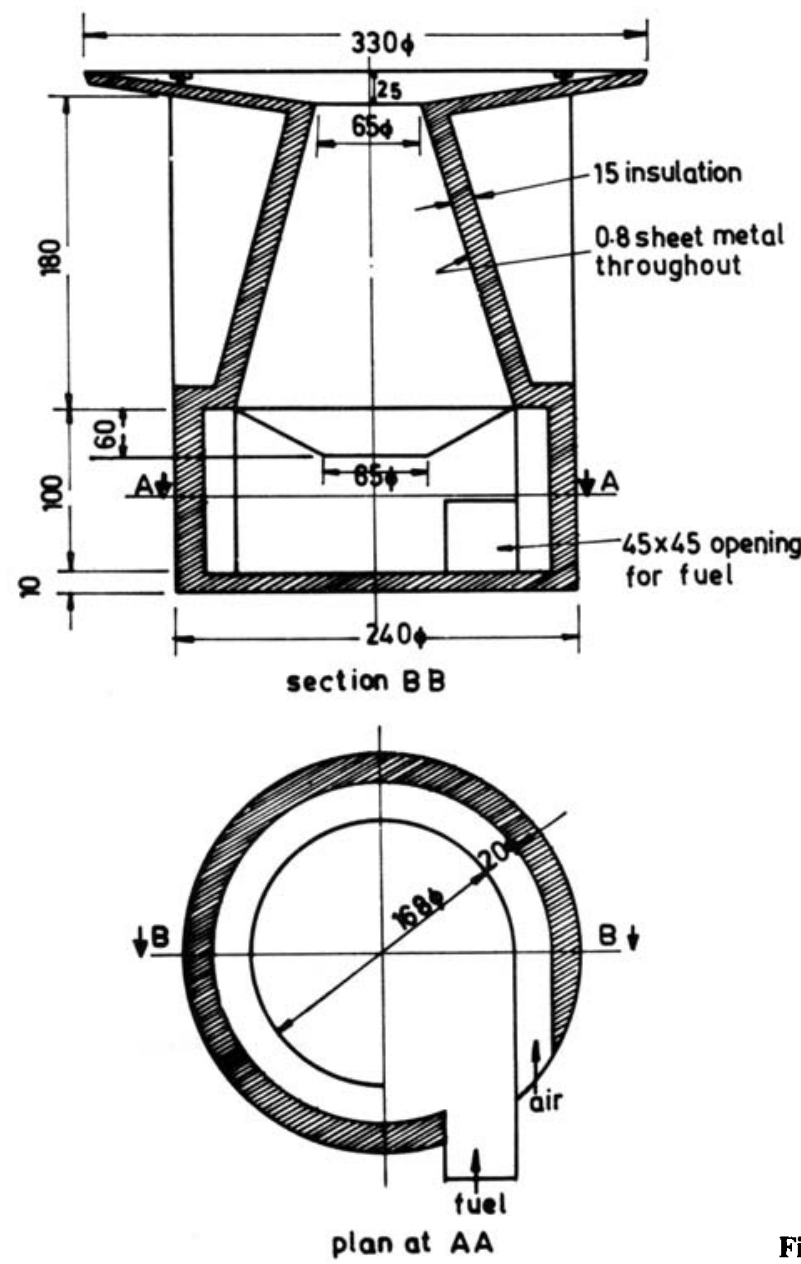

Figure 3b. Swosthee $2 \mathrm{~kW}-\mathrm{S}-2$.

cone diameter to a value greater than $0.045 \mathrm{~m}$ causes greater amounts of diffusion flame and hence more sooting. Decreasing this diameter to below $0.04 \mathrm{~m}$ allows reactions to produce intermediates without sooting and smoke but with components which cause eye-irritation and are therefore undesirable. Decreasing this diameter to below $0.03 \mathrm{~m}$ increases the resistance of the vertical path to such an extent that the air flow is not properly established and gases tend to flow outwards from air passages at the slightest wind disturbance. Increasing the stove height beyond $0.155 \mathrm{~m}$ does not enhance the quality of combustion; however decreasing it to below $0.120 \mathrm{~m}$ reduces the draft and thus the quality of combustion.

The conical part near the bottom plays an important role in enhancing the quality of combustion. At instantaneous heating rates of less than $1 \mathrm{~kW}$ or so, the flow has a recirculation zone which improves the combustion quality significantly. At larger heating rates the flame reaches upto the upper throat of the stove and causes some sooting of the vessel. There is, however, no smoke. In fact, if operated at power levels of $0.8-0.9 \mathrm{~kW}$, the functioning of the stove cannot be made out from a distance except when a significant amount of the charge suddenly pyrolyses and a puff of soot comes out. The extent of soot deposition on the vessel depends on the 
instantaneous power level of the system, which can be as much as one and a half times its average level. Combustion is aided significantly in the bottom enclosure which constitutes the major part of the combustion chamber and is maintained at high temperatures, of the order of $1000 \mathrm{~K}$.

During the development of the stove over a period, several changes have been introduced to reduce the cost of fabrication; figure 4 shows these changes. Use of two air inlets was dispensed with in favour of a single helical inlet. The method of fixing the conical choke plate, otherwise called quarl, was simplified. The major technical conclusions arrived at in this report are not affected by the changes indicated above as the conclusions have been verified in several cases with modified stoves.

\subsection{Efficiency measurement}

The efficiency of the stove is measured as follows, using a precedure similar to the

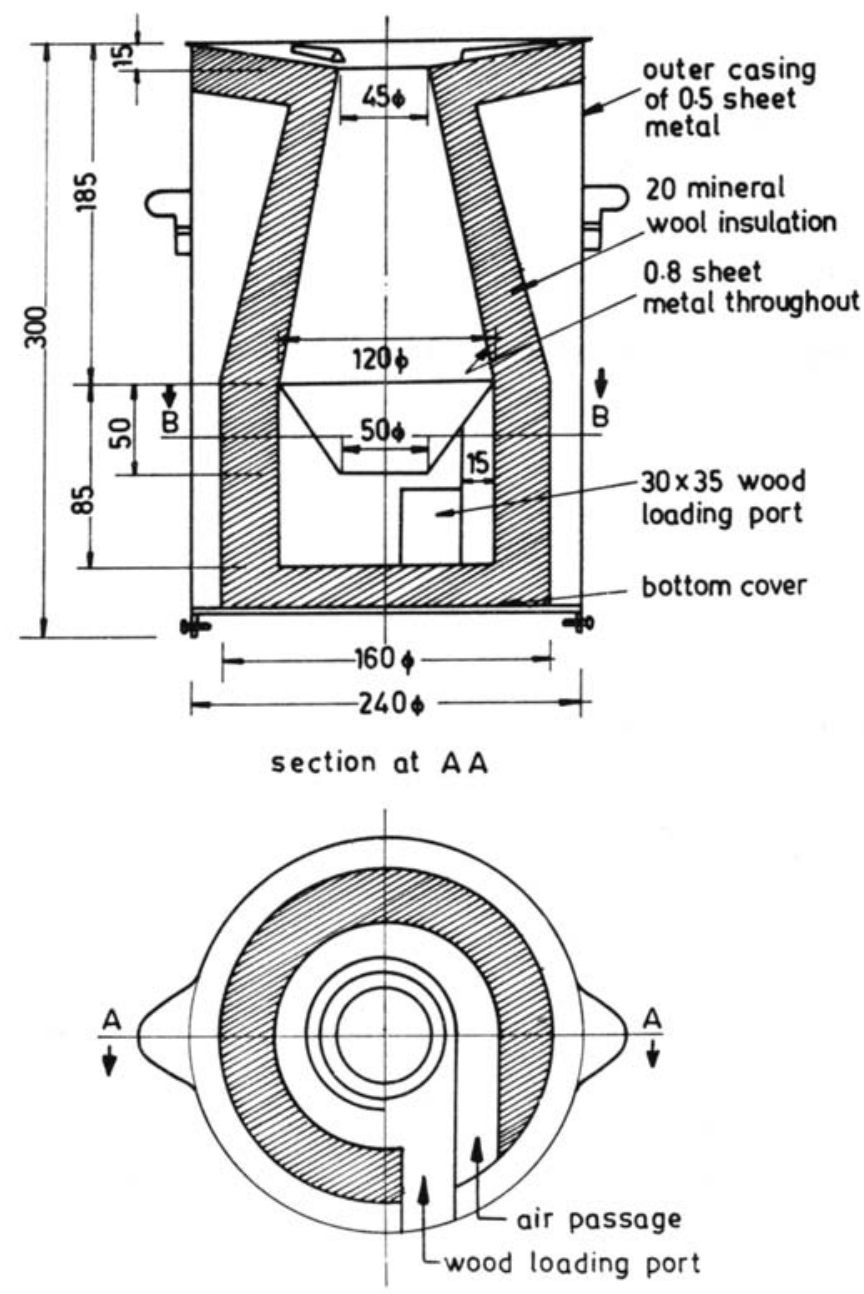

Figure 4. Swosthee $1 \mathrm{~kW}-\mathrm{S}-1$ (II)-Second prototype. 
one used by Eindhoven group but modified slightly to suit the low rated powers of Swosthee. It is assumed that the stove has to operate for $1 \mathrm{~h}$ during normal use. This is based on the day to day cooking requirements of a five-member family. The aluminium vessel used for the $1 \mathrm{~kW}$ stove was $0.125 \mathrm{~mm}$ thick, and of $0.25 \mathrm{~m}$ diameter and $0.125 \mathrm{~m}$ height. Each vessel was filled with $4 \mathrm{~kg}$ of water at ambient temperature, the quantity being chosen such that at $1 \mathrm{~kW}$ capacity it would take $1 \mathrm{~h}$ to bring the water to near boiling point. Since the condition after boiling would be difficult to measure (as evaporation losses are small as compared to the total mass), the upper limit of temperature was fixed at $365 \mathrm{~K}$ (368 $\mathrm{K}$ is the boiling point of water in Bangalore) and weight assumed to remain constant.

In early experiments, oven-dry casuarina wood was used. Subsequently, as received, and partially or even completely wet wood was used to evaluate the variation in performance with moisture content. For this purpose, moisture content was measured at the start of the experiment and the heat of combustion of the wood used was determined. The two are not independent, hence these measurements help in ensuring that the values of heat of combustion have a second check. The heat of combustion, i.e. lower calorific value (LCV) of wood, was correlated to the moisture content as

$$
\mathrm{LCV}=18 \cdot 3-20 \cdot 59 f(\mathrm{MJ} / \mathrm{kg}),
$$

where $f=$ moisture fraction in wood (wt basis).

Similar measurements for the charcoal produced in the stove during experiments indicated that

$$
\mathrm{LCV}=30 \cdot 5-32 \cdot 79 f(\mathrm{MJ} / \mathrm{kg}) \text {. }
$$

The quantities measured in the early experiments were weight of wood pieces loaded once every few minutes, gas temperature near the top throat, temperature of the water with time, initial total weight of wood pieces, final total weight of wood pieces and weight of charcoal or cinders remaining in the stove. The weight of unused charcoal was converted to equivalent unused wood by multiplying the weight of the charcoal with the ratio of the heat of combustion of charcoal to that of wood. The ratio of heat absorbed by the water and the vessel to the heat of combustion of wood used gives the efficiency. The average rate of consumption of wood multiplied by the heat of combustion gives the average power of the stove during operation.

\subsection{Results of efficiency tests}

Table 2 summarises the results of early tests. These results are also shown as a plot of efficiency versus power in figure 5 . As can be seen from the figure, efficiency is in the range of $43 \pm 3 \%$ over the range of powers tested. An interesting feature is that the efficiency is weakly dependent on the power even upto $65 \%$ of the rated power of the device. The points marked " 2 " belong to a second stove built to the same specifications in a lot of 200. This demonstrates that even when produced in quantity the mean performance of the stove can be expected to remain unaffected. Starting the stove takes about two minutes during which small splinters of wood along with some larger pieces can be ignited and pushed to the centre of the stove for a draft to be established. It is sometimes useful to supplement this with a small 
Table 2. Test data on 1 and $2 \mathrm{~kW}$ Swosthee stoves, S-1 (I) and S-2.

\begin{tabular}{|c|c|c|c|c|c|c|c|}
\hline $\begin{array}{l}\text { Initial water } \\
\text { temperature } \\
\text { (K) }\end{array}$ & $\begin{array}{l}\text { Time to raise } \\
\text { to } 365 \mathrm{~K}(\mathrm{~s})\end{array}$ & $\begin{array}{l}\text { Wood } \\
\text { used } \\
(\mathrm{kg})\end{array}$ & $\begin{array}{c}\text { Remaining } \\
\text { charcoal } \\
(\mathrm{kg})\end{array}$ & $\begin{array}{l}\text { Actual wood } \\
\text { used (kg) }\end{array}$ & $\begin{array}{c}\text { Power } \\
(\mathrm{kW})\end{array}$ & $\begin{array}{c}\text { Efficiency } \\
(\%)\end{array}$ & Stove used \\
\hline 302.0 & 4260 & 0.164 & 0.008 & 0.150 & 0.59 & 43.8 & S-1 (I) \\
\hline $300 \cdot 0$ & 3600 & 0.164 & 0.005 & 0.155 & 0.72 & $43 \cdot 6$ & S-1 (I) \\
\hline 301.0 & 3000 & $0 \cdot 193$ & 0.016 & 0.164 & 0.91 & $40 \cdot 6$ & S-1 (I) \\
\hline 301.0 & 2400 & 0.187 & $0-020$ & 0.151 & 1.00 & $44 \cdot 1$ & S-1 (I) \\
\hline 303.0 & 2640 & 0.180 & $0-011$ & 0.160 & 1.00 & $40 \cdot 3$ & S-1 (I) \\
\hline $300 \cdot 0$ & 3780 & 0.163 & 0.006 & 0.152 & 0.67 & 44.5 & S-1 (l) \\
\hline 301.0 & 2760 & $0 \cdot 166$ & 0.010 & 0.148 & 0.89 & 45.0 & S-1 (I) \\
\hline $300 \cdot 5$ & 2460 & 0.158 & 0.010 & 0.140 & 0.95 & $48 \cdot 0$ & S-1 (I) \\
\hline $300 \cdot 0$ & 3360 & 0.162 & 0.005 & $0-153$ & 0.74 & $44 \cdot 2$ & S-1 (I) \\
\hline $299 \cdot 0$ & 2820 & 0.382 & 0.033 & 0.322 & 1.90 & $41 \cdot 8$ & $\mathrm{~S}-2$ \\
\hline $302 \cdot 0$ & 3480 & $0-348$ & 0.020 & 0.312 & 1.50 & $41 \cdot 3$ & S-2 \\
\hline
\end{tabular}

Table 2a. Data on stoves S-1 (I) and S-2.

\begin{tabular}{lll}
\hline & S-1 (I) & S-2 \\
\hline Mass of metal (mild steel) (kg) & 1.54 & 1.90 \\
Mass of insulation (kg) & 1.0 & 1.37 \\
Mass of outer cover (kg) & 0.5 & 0.65 \\
Pans used, dia (m) & 0.245 & 0.31 \\
Height (m) & 0.11 & 0.12 \\
Thickness (mm) & 1.25 & 1.25 \\
Mass (kg) & 0.785 & 0.855 \\
\hline
\end{tabular}

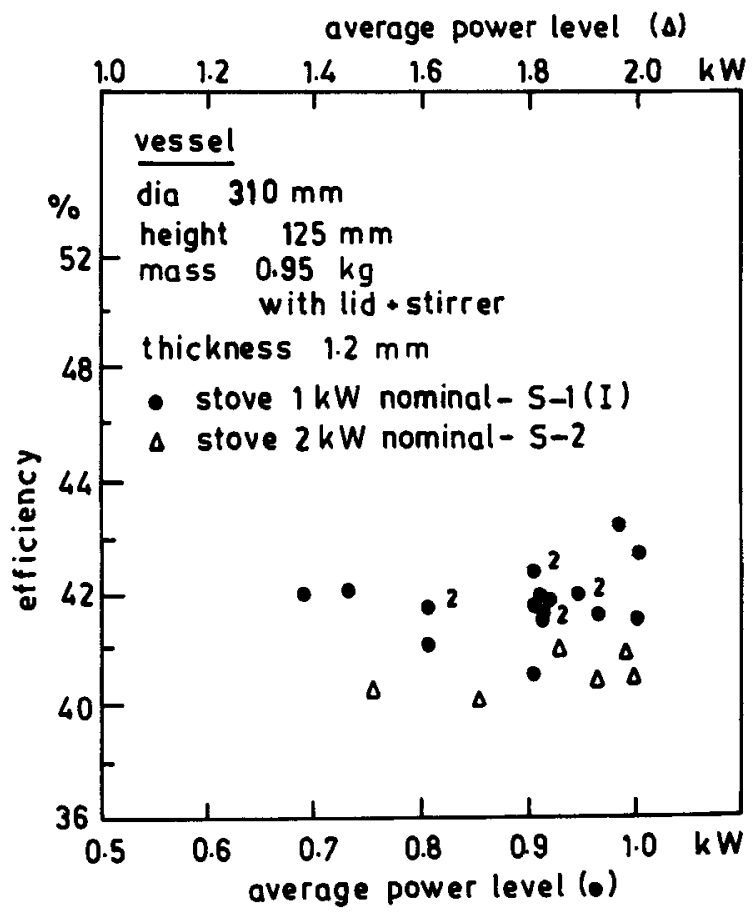

Figure 5. Measured efficiencies of 1 and $2 \mathrm{~kW}$ Swosthees. ' 2 ' refers to a second stove built to the same specifications as S-1 (I) but in a lot of 200 numbers. 
piece of rag soaked in kerosene to establish the flame. The system should be started on low heat till the draft is well-established, which takes about twelve minutes, by which time even the inner wall temperature crosses $900 \mathrm{~K}$. After this, continual loading of wood pieces once in five minutes or so would be adequate to keep the stove going at its nominal power.

\subsection{The $2 \mathrm{~kW}$ stove}

The dimensions of the $2 \mathrm{~kW}$ stove, S-2, scaled from the $1 \mathrm{~kW}$ stove are shown in figure 3 itself. The basis for scaling is the mass flux in various flow paths. It is maintained at the same level to ensure that the average stay time of gases is about the same both in 1 and $2 \mathrm{~kW}$ stoves. This calls for doubling of all flow crosssectional areas. It is not clear whether the height of the stove could be kept the same. Only some marginal changes have been made in other dimensions, particularly the height. This stove has been tested for its efficiency and results are shown in figure 5 . All efficiency values exceed $40 \%$. It is believed that these values can be raised by $5-6 \%$ through appropriate geometric modifications which are yet to be undertaken. The sooting is also about the same as in the previous case. Attempts to overcome sooting are discussed later.

\section{Factors contributing to high performance}

In the early part of the work it was thought that good mixing alone was responsible for the high efficiency of the stove. To verify this, we intended to measure the air flow rate. Since it is more complicated to measure the air flow rate during natural aspiration, air was supplied using a blower through the air inlet at a metered rate which was varied until the average combustion in the stove appeared to be similar to that observed during normal operation. During these experiments it was found that normal combustion was obtained only over a narrow range of air-supply rates. These were measured using a rotameter in the line coming from the blower. Table 3 contains results of blower-run experiments. The table shows that $A / F$, the air to fuel ratio, during the operation is between 6.5 and 7.0 . These values may be in slight error because air would have been taken in from the fuel-loading port during the loading operation (during other times the port was closed). The error could be about $20 \%$. This puts the $A / F$ at 7.8 to 8.4 , about $25 \%$ above stoichiometric $A / F$ (which is 6.5 for wood). Stoichiometry is the condition which leads to maximum temperature of the fuel-air mixture. As will be subsequently shown in connection

Table 3. Air-fuel ratio measurement for S-1 (I).

\begin{tabular}{lccccccc}
\hline $\begin{array}{l}\text { Amount } \\
\text { of water } \\
\text { taken }(\mathrm{kg})\end{array}$ & $\begin{array}{c}\text { Air } \\
\text { Plow } \\
(\mathrm{kW})\end{array}$ & $\begin{array}{c}\text { Fuel } \\
\text { rate } \\
(\mathrm{g} / \mathrm{s})\end{array}$ & $\begin{array}{c}\text { used } \\
(\mathrm{kg})\end{array}$ & $\begin{array}{c}\text { Duration } \\
\text { of opera- } \\
\text { tion }(\mathrm{s})\end{array}$ & $\begin{array}{c}\text { Average } \\
\text { fuel } \\
\text { burn rate } \\
(\mathrm{g} / \mathrm{s})\end{array}$ & $\begin{array}{c}\text { Efficiency } \\
(\%)\end{array}$ & $A / F$ \\
\hline 4 & 1.03 & 0.40 & 0.177 & 2880 & 0.061 & 38.0 & 6.5 \\
4 & 0.91 & 0.40 & 0.162 & 2700 & 0.056 & 46.0 & $7 \cdot 1$ \\
4 & 0.93 & 0.34 & 0.168 & 3000 & 0.056 & $41 \cdot 1$ & 6.1 \\
4 & 0.96 & 0.36 & 0.188 & 3300 & 0.051 & 38.0 & $7 \cdot 1$ \\
\hline
\end{tabular}


with experiments on sooting, the efficiency peaks at the stoichiometric $A / F$ or at slightly fuel-rich conditions. A further confirmation of the normal operation of the stove was obtained by measuring the oxygen mole fraction in the gases at the outlet. The results indicated a mean figure of $6-10 \%$ by volume for the $1 \mathrm{~kW}$ stove, S-1 (I), which corresponds to an excess air weight fraction of about $12-18 \%$, roughly agreeing with the values discussed earlier.

The efficiency of the stove is dependent on several factors-period of run, moisture in the wood, ambient wind conditions and vessel size.

Figure 6 shows the efficiency of Swosthee-1 kW stove, S-1 (I)-as a function of moisture content. Though there is no regular variation of the efficiency, it is better than $40 \%$ in almost all cases.

It was noticed during the tests that efficiency has a weak dependence on the duration of the run. This was considered reasonable because during the starting of the stove, the major portion of the heat liberated could be expected to heat up the inner walls of the stove. To elucidate this point, tests of varying duration were undertaken with a fixed vessel. Results are shown in figures 7 and 8 . Figure 7 shows that for durations greaier than $30 \mathrm{~min}$, the efficiency crosses $40 \%$. Since cooking with the stove could be taken to be of around one-hour duration, the benefits of high efficiency are assured; cooking for longer durations shows a slight drop in efficiency.

Figure 8 shows a plot of time taken to heat a unit mass of water to $365 \mathrm{~K}$ versus the total quantity of water being heated. The graph shows a flat region around $480 \mathrm{~s} / \mathrm{kg}$ for $8-12 \mathrm{~kg}$ of water. The way to interpret this curve is as follows. If a very large quantity is being heated by a low capacity stove, the difference between heating rate and heat loss rate from the vessel becomes lower and the effect of heat loss rate becomes significant. This causes the average time taken to heat $1 \mathrm{~kg}$ of water to rise. In the extreme limit of large quantities, almost all the heat input into the vessel is lost. A similar feature is seen with lower amounts of water where the heat absorbed by the stove body begins to have significant effect on the time taken to heat a unit quantity of water. The same result shown in terms of weight of wood



Figure 6. Variation of the efficiency of Swosthee $1 \mathrm{~kW}-\mathrm{S}-1$ (I) with moisture content of fuel wood. 


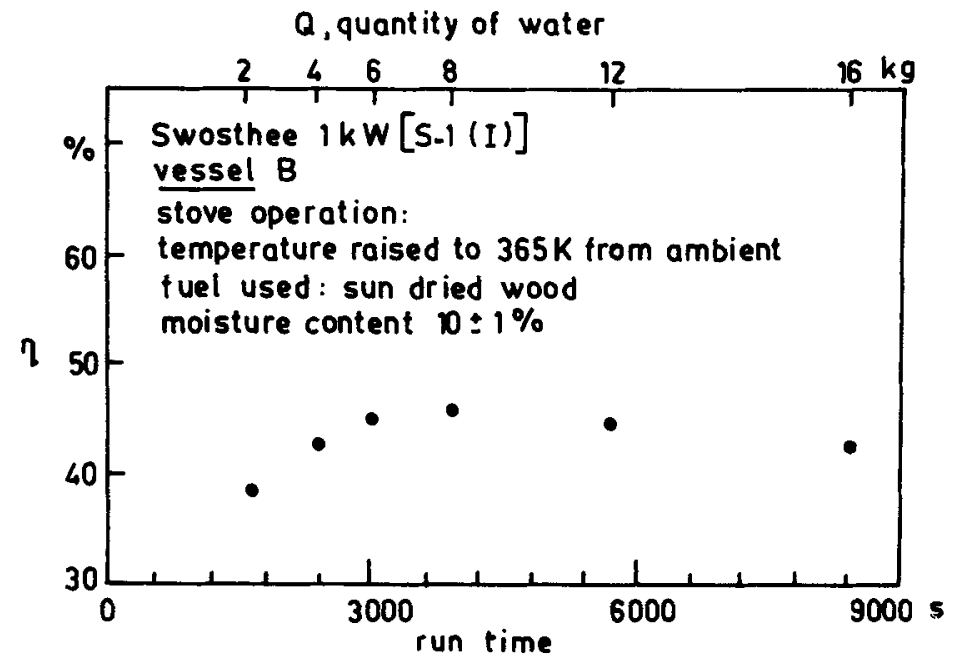

Figure 7. Variation of efficiency of Swosthee $1 \mathrm{~kW}-\mathrm{S}-1$ (I) with duration of stove operation.

used per unit quantity of water being heated is also presented in figure 8 and displays a similar optimum.

The results brought out in these figures are consistent with the elementary principles of heat transfer noted earlier and have an important effect on the choice of power of the stove. Using a stove of unnecessarily high power will imply that the benefits of high efficiency of the stove are not realized during normal usage. To illustrate the point, consider a family of 5-6, which cooks about $5 \mathrm{~kg}$ of food every day. The amount of water required for this cooking is about $12 \mathrm{~kg}$. The total equivalent amount of water to be boiled can be taken to be about $15 \mathrm{~kg}$. Figure 7 shows that it needs about $7800 \mathrm{~s}(130 \mathrm{~min})$ to perform this operation and the point is already in the lower efficiency region. Figure 8 indicates that it is about $8 \%$ away from the optimal. An important criterion for the wood stove is that cooking should

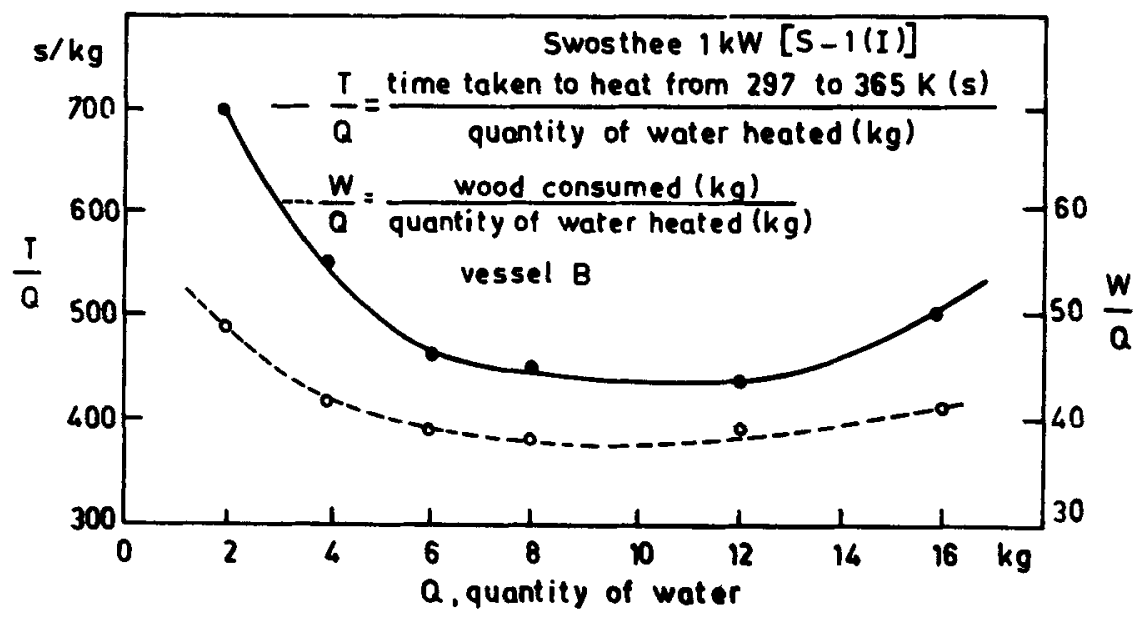

Figure 8. Variation of $T / Q$ and $W / Q$ with the quantity of water heated. 
be completed in about an hour's time. This implies that the power of the stove should be doubled implying the need for single-pan stoves with reasonably high efficiency (about 40\%) designed for power levels of $1.5-2.5 \mathrm{~kW}$. This and other aspects concerning how vessel size determines efficiency will be discussed again later.

One of the important factors contributing to the high efficiency of Swosthee is the height of the gap between the bottom of the vessel and the stove top-plate. The gap is controlled by spacers. To make the spacer adaptable to various vessel sizes, it was argued that a flat-bottomed vessel should make contact with the spacers only at the outer periphery of the vessel and the gas flow passage there should have about the same cross-section as the flue gas outlet of the stove.

This amounts to the spacer height $h$, at any diameter $d$ of contact, being $\left(h / d_{t}\right)=\left(d_{t} / 4 d\right)$, where $d_{t}$ is the diameter of the flue gas outlet, to maintain equal areas for the flow of flue gases. Therefore the spacer should be hyperbolic in shape with $h / d_{t}=1 / 4$ at $d=d_{t}$. The shape of the spacer is as shown in figure 9 . The stove top should be made conical and the cone angle should be more than $\tan ^{-1}(0 \cdot 25)=14^{\circ}$ as given by the slope of the spacer at the stove outlet. This is to make sure that any vessel with a flat bottom and a given diameter can be supported at its bottom periphery properly.

While a prototype was being fabricated careful attention was not paid to the spacer dimensions and, during a test, efficiency dropped from $42 \%$ to $32 \%$ and combustion was smoky. However, when the spacer was modified to provide the necessary gap, efficiency increased to $42 \%$ and smoke was virtually eliminated, indicating the necessity of tuning this parameter for good stove performance.

\section{Sooting of vessels}

During early tests it was observed that Swosthee has the problem of sooting even though it does not produce any smoke. No measurements of the soot levels were made at that time and experiments carried out to determine the efficiency by water boiling tests used only oven-dry casuarina wood. This was to maintain uniformity in the quality of wood and also to reduce the number of experiments required for determining the heat of combustion. During efficiency tests significant sooting was noticed. For subsequent cooking experiments, however, only sun-dried wood was used. It was then observed that very little sooting of the vessels occurred. Hence



Figure 9. Shape of the spacer used at the stove top. 
systematic measurements were made of the amount of soot collected on the vessels in all subsequent tests. After each run of 50 to $90 \mathrm{~min}$, soot was scraped from the vessel, collected and weighed. Results obtained are shown in table 4 along with values of efficiency and a few other details. As can be seen from the table, soot deposition is very significant in stove S-1 (I) (see table 1 for the notation) which has slightly lower air inlet area and its efficiency is indeed high. Reduced sooting is correlated with reduced efficiency. Experiments conducted with sun-dried wood resulted in a relatively smaller amount of fine soot deposited on the vessel; collection of soot for measurements proved difficult. What the upper limit could have been was estimated as indicated in rows 7 and 8 of table 4. Apart from the vessel surface, the deposition of soot also occurred on the upper part of the stove body. The sample collected appears to be close to carbon black though it has not been analysed as yet.

To avoid sooting of the vessels a flat, circular mild steel plate of $0.8 \mathrm{~mm}$ thickness and another of aluminium of $1.6 \mathrm{~mm}$ thickness and the same diameter as the top of the stove were introduced between the stove body and the vessel. These resulted in a fall in efficiency of about 5 and $3 \%$ respectively as indicated in table 4 . The drop in efficiency appears to be a reasonable sacrifice for keeping the vessel clean.

\section{Emissions}

A visiting research worker, Ms. Jamuna Ramakrishnan from the University of Hawaii, came to our Institute with the intention of measuring emissions from the stoves during tests. During her visit, measurements were made of the $\mathrm{CO}(\mathrm{ppm})$ and particulate matter levels $\left(\mathrm{mg} / \mathrm{m}^{3}\right)$ in kerosene and wood stoves. A comparison between the two is shown in table 5 . The tabulated results were obtained from water boiling tests, the duration of each test being $1 \mathrm{~h}$.

Measurements were made in a closed room (dimensions-3 $\mathrm{m} \times 4 \mathrm{~m} \times 3 \mathrm{~m}$ ) keeping one set of sensors pinned on to the shirt collar of the person using the stove, while another set was kept in the vicinity. The emission levels of $\mathrm{CO}$ from the wood stoves S-1 (I) and S-2 of 5 and $6 \mathrm{ppm}$ (peak), respectively, were less than the $25 \mathrm{ppm}$ (peak) from a kerosene stove and the 9 and $35 \mathrm{ppm}$ limitation of National Air Quality Standards (both primary and secondary) of USA (Sittig 1974, as quoted

Table 4. Measurements of soot deposition on vessels.

\begin{tabular}{lccccc}
\hline $\begin{array}{l}\text { Duration } \\
\text { (s) }\end{array}$ & $\begin{array}{c}\text { Power } \\
(\mathrm{kW})\end{array}$ & $\begin{array}{c}\text { Water used } \\
(\mathrm{kg})\end{array}$ & $\begin{array}{c}\text { Efficiency } \\
(\%)\end{array}$ & $\begin{array}{c}\text { Soot quantity } \\
(\mathrm{g} / \mathrm{s})\end{array}$ & Stove model \\
\hline 4620 & 1.05 & 8 & 46.5 & 0.108 & S-1 (I) \\
5100 & 1.02 & 8 & 42.4 & 0.078 & S-1 (II) \\
5400 & 0.98 & 8 & 41.0 & 0.064 & S-I (II) \\
3600 & 1.55 & 8 & 40.3 & 0.039 & S-2 \\
4620 & 1.01 & 8 & 47.8 & 0.117 & S-1 (I) \\
2880 & 1.03 & 4 & 38.0 & 0.036 & S-1 (II) \\
3240 & 1.02 & 4 & 41.0 & $0.006^{* *}$ & S-1 (I) \\
3360 & 0.90 & 4 & 42.0 & $0.004^{* *}$ & S-1 (I) \\
2400 & 1.21 & 2 & 37.7 & - & S-1 (III) \\
3000 & 1.10 & 4 & 35.0 & - & S-1* (III) \\
\hline
\end{tabular}

**With wood of $12 \cdot 15 \%$ moisture content.

*using a mild steel plate: ${ }^{+}$an aluminum plate. 
Table 5. Emission of $\mathrm{CO}$ and particulate matter.

\begin{tabular}{|c|c|c|c|}
\hline & \multirow{2}{*}{$\begin{array}{l}\text { Kerosene stove } \\
\text { (Amar } 10 \text { wick) }\end{array}$} & \multicolumn{2}{|c|}{ Wood stove* } \\
\hline & & $S-1(I)$ & $\mathrm{S}-2$ \\
\hline Power $(\mathrm{kW})$ & $1-1 \cdot 5$ & 1 & 2 \\
\hline $\mathrm{CO}(\mathrm{ppm})$ & 25 (peak) & 5 (peak) & 6 (peak) \\
\hline Particulate matter $\left(\mathrm{g} / \mathrm{m}^{3}\right)$ & $0 \cdot 19$ & 0.89 & $2 \cdot 4$ \\
\hline
\end{tabular}

in Sulilatu 1985) for an average exposure time of 1 and $8 \mathrm{~h}$ respectively. These emission levels must be compared with the levels quoted by Agarwal et al (1983) of $56 \mathrm{mg} / \mathrm{m}^{3}$ (about $56 \mathrm{ppm}$ ) for the highest they had come across, and $7 \mathrm{mg} / \mathrm{m}^{3}$ (about $7 \mathrm{ppm}$ ) the average value, from their measurements in a number of kitchens. The low emission levels were not anticipated, but were gratifying nonetheless. It is also clear that a chimney is indeed not necessary to exhaust the pollutants from the kitchen; instead they can be eliminated at the point of generation itself.

Even with respect to particulates the emissions of $0.89 \mathrm{mg} / \mathrm{m}^{3}$ from S-1 (I) is just within the National Primary Air Quality Standard of USA of $0.075 \mathrm{mg} / \mathrm{m}^{3}$ as the annual geometric mean if we assume that a day's cooking is confined to $2 \mathrm{~h}$. However the emission from S-2 exceeds standards. A quick inspection of the particulate matter deposited on the filters used in the sensors showed that it was mostly ash. From the design of the system it is to be expected that some ash would fly along with the flue gases and float around in the environment. The estimated particle size is more than 3 microns and such particles are held back in the nostrils and will not enter the lungs of the person involved in cooking.

\section{Cooking experiments}

To evaluate the economics of the stove, a number of experiments with actual cooking sequences were conducted. In South India a typical day's cooking consists of the following.

* $1 \mathrm{~kg}$ of rice with 2.5 to $3 \mathrm{~kg}$ of water depending on the quality of rice and the needs of the family,

$* 0.25 \mathrm{~kg}$ of pulses or lentils (dal) with $1.6 \mathrm{~kg}$ of water $+0.3 \mathrm{~kg}$ of potatoes or other vegetables,

$* 0.5 \mathrm{~kg}$ of ragi balls (a kind of millet porridge) in some areas,

* $0.75 \mathrm{~kg}$ of chapathis (flat thin wheat bread) in some areas.

Experiments were conducted on both kerosene and wood stoves of comparable power. A stove of $1 \mathrm{~kW}$ nominal capacity (S-1 (I)) was chosen and rice and dal were cooked on kerosene and wood stoves on alternate days. In ten days of testing, five comparable sets of data were generated. These are shown in tables $6 \mathrm{a}$ to $6 \mathrm{~d}$.

During cooking experiments, only sun-dried wood was used to simulate normal cooking in most houses. As can be noticed from table $6 \mathrm{a}$, about $20-30 \mathrm{~g}$ of water is lost by evaporation during cooking. Table 7 shows that the average quantity of wood consumed per kilogram of raw rice is $0.22 \mathrm{~kg}$. Krishna Prasad (1985a) has 
Table 6a. Cooking tests with rice on S-1 (I) and Amar.

Rice $1 \mathrm{~kg}+$ water

\begin{tabular}{lcccccc}
\hline $\begin{array}{l}\text { Water used } \\
(\mathrm{kg})\end{array}$ & $\begin{array}{c}\text { Food cooked } \\
(\mathrm{kg})\end{array}$ & $\begin{array}{c}\text { Wood used } \\
(\mathrm{kg})\end{array}$ & $\begin{array}{c}\text { Kerosene used } \\
(\mathbf{k g})\end{array}$ & $\begin{array}{c}\text { Power } \\
(\mathbf{k W})\end{array}$ & SFC-1 & SFC-2 \\
\hline 2.70 & 3.68 & 0.210 & - & 0.98 & 0.210 & 0.0570 \\
2.70 & 3.65 & 0.200 & - & 0.93 & 0.200 & 0.0550 \\
2.70 & 3.67 & 0.225 & - & 0.96 & 0.225 & 0.0610 \\
2.55 & 3.60 & 0.220 & - & 1.02 & 0.200 & 0.0610 \\
2.70 & 3.68 & - & 0.055 & 0.90 & 0.055 & 0.0150 \\
2.70 & 3.65 & - & 0.060 & 0.98 & 0.060 & 0.0164 \\
2.50 & 3.45 & - & 0.050 & 0.84 & 0.050 & 0.0145 \\
2.50 & 3.57 & - & 0.065 & 1.06 & 0.065 & 0.0180 \\
\hline
\end{tabular}

Ratio of weight of wood to kerosene $=3.8$ to $4 \cdot 0$; SFC-1 $-\mathrm{kg}$ of fuel per $\mathrm{kg}$ of raw rice used in cooking; SFC-2-kg of fuel per $\mathrm{kg}$ of cooked food.

Table 6b. Cooking tests with dal and vegetables on S-1 (I) and Amar.

Dal: $0.25 \mathrm{~kg}+$ water: $1.65 \mathrm{~kg}$ + vegetables: $0.3 \mathrm{~kg}$ (total $2.20 \mathrm{~kg}$ )

\begin{tabular}{|c|c|c|c|c|c|}
\hline $\begin{array}{l}\text { Time to cook } \\
\text { (s) }\end{array}$ & $\begin{array}{c}\text { Food cooked } \\
(\mathrm{kg})\end{array}$ & $\begin{array}{c}\text { Wood used } \\
(\mathrm{kg})\end{array}$ & $\begin{array}{l}\text { Kerosene used } \\
\text { (kg) }\end{array}$ & $\begin{array}{c}\text { Power } \\
(\mathrm{kW})\end{array}$ & SFC \\
\hline 4800 & 2.04 & - & $0 \cdot 100$ & 0.91 & 0.049 \\
\hline 4500 & 2.04 & - & 0.085 & 0.83 & 0.042 \\
\hline 5100 & $2 \cdot 10$ & - & 0.085 & 0.69 & 0.041 \\
\hline 3600 & 1.98 & - & 0.090 & $1 \cdot 10$ & 0.045 \\
\hline 4500 & $2 \cdot 12$ & 0.30 & - & $1 \cdot 10$ & $0-141$ \\
\hline 5400 & $2 \cdot 20^{*}$ & $0 \cdot 31$ & - & 0.96 & $0 \cdot 141$ \\
\hline 5400 & 2.04 & 0.31 & - & 0.96 & 0.152 \\
\hline 4800 & 2.05 & $0 \cdot 30$ & - & 1.08 & 0.146 \\
\hline
\end{tabular}

Wood : kerosene $=3.6 ;{ }^{*} 1.7 \mathrm{~kg}$ water; $\mathrm{SFC}-\mathrm{kg}$ of fuel used per $\mathrm{kg}$ of food cooked.

Table 6c. Cooking tests with ragi on S-1 (I) and Amar.

Ragi: $0.5 \mathrm{~kg}+$ water $1 \mathrm{~kg}$ (total $1.5 \mathrm{~kg}$ )

\begin{tabular}{lccccc}
\hline $\begin{array}{l}\text { Time to cook } \\
(\mathrm{s})\end{array}$ & $\begin{array}{c}\text { Food cooked } \\
(\mathbf{k g})\end{array}$ & $\begin{array}{c}\text { Wood used } \\
(\mathbf{k g})\end{array}$ & $\begin{array}{c}\text { Kerosene } \\
(\mathbf{k g})\end{array}$ & $\begin{array}{c}\text { Power } \\
(\mathrm{kW})\end{array}$ & SFC \\
\hline 1500 & 1.40 & - & 0.035 & 1.02 & 0.025 \\
1200 & 1.39 & - & 0.030 & $1 \cdot 10$ & 0.021 \\
2100 & 1.44 & 0.10 & - & 0.80 & 0.069 \\
1800 & 1.39 & 0.11 & - & 1.02 & 0.079 \\
1800 & 1.41 & - & 0.030 & 0.73 & 0.021 \\
\hline
\end{tabular}

Wood $:$ kerosene $=3 \cdot 5 ;$ SFC $-\mathrm{kg}$ of fuel used per $\mathrm{kg}$ of food cooked.

Table 6d. Cooking tests with wheat flour on S-1 (I) and Amar.

Wheat flour: $0.5 \mathrm{~kg}+$ water: $0.25 \mathrm{~kg}$, (total: $0.75 \mathrm{~kg}$ )

\begin{tabular}{lccccc}
\hline $\begin{array}{l}\text { Time to } \\
\text { cook } \\
(\mathrm{s})\end{array}$ & $\begin{array}{c}\text { Food } \\
\text { cooked } \\
(\mathrm{kg})\end{array}$ & $\begin{array}{c}\text { Wood } \\
\text { used } \\
(\mathrm{kg})\end{array}$ & $\begin{array}{c}\text { Kerosene } \\
\text { used } \\
(\mathrm{kg})\end{array}$ & $\begin{array}{c}\text { Power } \\
(\mathrm{kW})\end{array}$ & SFC \\
\hline 2400 & 0.700 & - & 0.045 & 0.8229 & 0.064 \\
2100 & 0.720 & - & 0.030 & 0.6270 & 0.041 \\
1800 & 0.750 & 0.130 & - & 1.2000 & 0.180 \\
2700 & 0.720 & 0.150 & - & 0.9288 & 0.209 \\
2700 & 0.750 & 0.200 & - & 1.2300 & 0.267 \\
\hline
\end{tabular}

Wood : kerosene $=40:$ SFC $-\mathrm{kg}$ of fuel used per $\mathrm{kg}$ of food cooked. 
Table 7. Summary of cooking results on S-1 and Amar.

\begin{tabular}{ll}
\hline Mean power level & $1 \mathrm{~kW}$ \\
Efficiency of wood stove & $42 \pm 2 \%$ \\
Efficiency of kerosene stove & $48 \pm 4 \%$ (sensitive to wind conditions) \\
Fuel consumed & $0.22 \pm 0.02 \mathrm{~kg}$ wood \\
per kg of raw rice & $0.057 \pm 0.003 \mathrm{~kg}$ kerosene \\
& $0.058 \pm 0.002 \mathrm{~kg}$ wood \\
per kg of cooked rice & $0.0158 \pm 0.0002 \mathrm{~kg}$ kerosene \\
& \\
Fuel consumed & $0.140 \pm 0.005 \mathrm{~kg}$ wood \\
per kg of cooked food when items other than & $0.034 \pm 0.003 \mathrm{~kg}$ kerosene \\
\hline
\end{tabular}

indicated that an 'ideal' stove should consume $0.24 \mathrm{~kg}$ of wood for cooking $1 \mathrm{~kg}$ of rice based on his 'Maize Diamond'. The average consumption obtained here is slightly lower than the value indicated by him.

It can be seen from table 8 that for cooking, costs of unit energy based on wood and kerosene are comparable at the most expensive rates for wood (as found in cities) with wood having an edge over kerosene in rural and semi-urban areas; use of electrical energy is the costliest. Therefore, to be economical one must avoid electrical energy for heating or cooking.

The ratio of consumption of wood to that of kerosene for similar cooking jobs is $3 \cdot 5$ to 4 .

The cost of kerosene in the Indian market is $\operatorname{Rs} 2 \cdot 80 / \mathrm{kg}$ ( $\operatorname{Rs~} 2 \cdot 25 /$ litre at the time of preparing this report). The maximum cost of wood cut to small pieces is Rs $0.70 / \mathrm{kg}$ in Bangalore. In semi-urban markets it is about $0.5-0.55 \mathrm{Rs} / \mathrm{kg}$. The ratio of the cost per kilogram of kerosene to that of wood is therefore $4: 1$. Hence it will cost about the same to cook with Swosthee using wood for a normal day's cooking in city areas as it would cost if a kerosene stove is used. However, in semiurban and rural areas, cooking with Swosthee is likely to be cheaper, at least by $25-30 \%$ depending on the price of wood (see tables 6, 7 and 8 ).

\section{Recent high efficiency stove designs}

After Swosthee $1 \mathrm{~kW} \mathrm{S-1}$ (I) and $2 \mathrm{~kW} \mathrm{S-2}$ stoves were developed and while they

Table 8. Energy for cooking $1 \mathrm{~kg}$ raw rice.

\begin{tabular}{lcccc}
\hline $\begin{array}{l}\text { Source of } \\
\text { energy }\end{array}$ & $\begin{array}{c}\text { Power } \\
(\mathrm{kW})\end{array}$ & $\begin{array}{c}\text { Duration } \\
(\mathrm{s})\end{array}$ & $\begin{array}{c}\text { Cost of unit } \\
\text { energy (Rs/MJ) }\end{array}$ & $\begin{array}{c}\text { Energy } \\
\text { cost (Rs) }\end{array}$ \\
\hline Electrical & 1.0 & 2700 & 0.13 & 0.32 \\
& & $1800^{*}$ & & 0.24 \\
Kerosene (Amar) & 1.0 & 2700 & 0.067 & 0.16 \\
Wood S-1 (I) & 1.0 & 3600 & $0.042-0.047$ & 0.16 \\
\hline
\end{tabular}

*A very efficient stove which has an automatic switch for cutting off power at the appropriate time during cooking. At the time of the preparing the report the cost of kerosene was Rs 2.25 per litre and that of wood, Rs 0.7 per $\mathrm{kg}$. 
were being field tested, it became clear on discussion with several users in villages that they do not formally distinguish between smoke and soot, though one user did remark that this stove produces 'smoke' which does not hurt the eyes and is not irritating.

Since total elimination of smoke was not important, alternate design concepts for high efficiency were investigated. Swosthee essentially aims at better mixing of the fuel and the oxidant i.e. air, to produce better combustion. To achieve high efficiency, it crucially depends on efficient convective heat transfer i.e. better heat transfer coefficient which depends on flow rate, dimensions (or the Reynolds number to be precise) and the temperature differential between the gas phase and the surface of the vessel. If one achieves good premixing the temperature of the gas will be a function of mixture ratio, and if the effective mixture ratio departs significantly from stoichiometry, the gas temperature will be lower. On the other hand, if one allows diffusive combustion to operate, the flame temperature will be close to stoichiometry in significant regions of the flame and this enhances the potential for heat transfer on the average. The essential difference between the two modes is in terms of how effectively the combustion is completed. Swosthee is expected to achieve it much better than a design which employs a diffusive mode of combustion.

Swosthee-1 kW, the S-1 (M) (in its later version), has a relatively small fuel loading port of $0.03 \mathrm{~m} \times 0.035 \mathrm{~m}$ calling for preparation of small pieces of fuel, which is considered a drawback by users. Generation of small pieces of fuel is not considered difficult from the forest technology point of view. "Short rotation, closelyplanted fuel wood stick projects are proposed as an appropriate strategy to increase fuel wood production... despite a number of caveats, such systems are economically viable and possibly superior to conventional forestry solutions". (Van Gelder et al 1983).

However if the fuel loading port were larger users may load more wood than required and operate the stove at larger power levels, with the accompanying incomplete combustion, particularly in the case of the $1 \mathrm{~kW}$ stove, because many users need more than $1 \mathrm{~kW}$ for cooking. Enlarging the fuel loading port substantially and keeping the power limited to $1.5-2 \mathrm{~kW}$ (say), could cause a reduction in the height of the draft column and the swirl, due to a part of the air supply entering through the fuel loading port instead of the tangential entry.

Therefore a conceptually different design (MS-1.5, and MS-4) for a high efficiency stove was evolved which involved the burning of wood on a grate; the height of the stove beyond the grate was limited to the height of the diffusion flame at the average power level so that flue gases, with temperature close to the adiabatic temperature expected in a diffusion flame, are produced. Further a perforated cylindrical chamber around the flame is added so that the flame can draw air from several points, thus reducing its dependence for combustion on the air flow drawn from the fuel loading port, which may vary with the charge loaded. The diameter of the perforated chamber is so chosen that it limits the length of the fuel pieces which in turn limits the power. Thus if the user tries to pack the fuel loading region, the peak power gets limited by the length of the fuel sticks on the grate, which is equal to the diameter of the perforated cylinder. Figure 10 shows the two modified Swosthees, stoves of $1.5 \mathrm{~kW}$ (MS-1.5) and $4.0 \mathrm{~kW}$ (MS-4) nominal power, built based on the above design. 


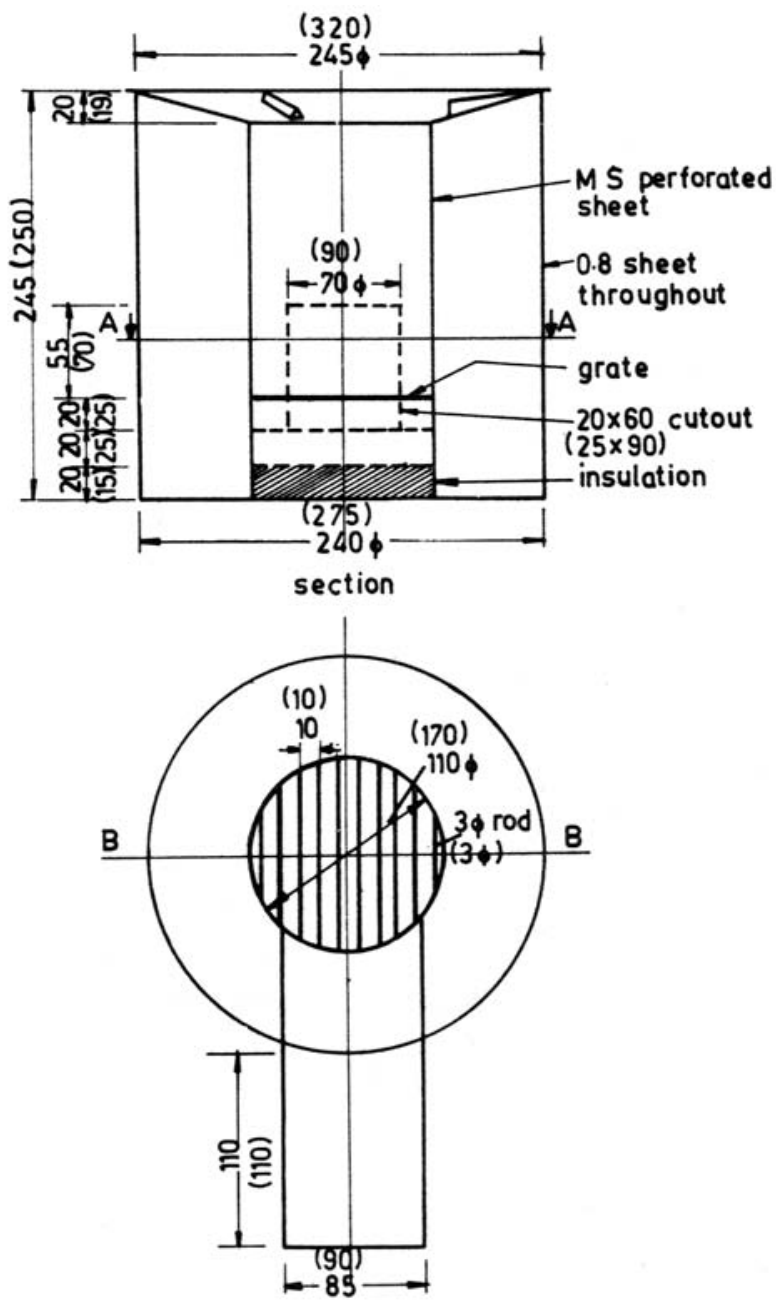

Figure 10. Details of Modified Swosthees, MS-1.5 (and MS-4). Numbers in parentheses refer to MS-4.

The power of the stove can be varied by a factor of 1.5 or so by choosing the size of wood pieces being loaded. If thin sticks of about $0.0035 \mathrm{~m}$ diameter are used, power would be close to one and a half times the nominal. If $0.02 \mathrm{~m}$ diameter sticks are used then the power is about the nominal or $10 \%$ less depending on the attention paid to pushing the sticks in.

Around the time these new designs were being fabricated the authors' attention was drawn to two other stoves being marketed as reasonably high efficiency stoves. These are called Priyagni (designed by the Central Power Research Institute, Bangalore) and Tara (designed by the Development Alternatives, New Delhi). Priyagni has two models - one goes up to $2.5 \mathrm{~kW}$ (P-S) and the other up to $3.5 \mathrm{~kW}$ (P-M) (the designer refers to these as meant for cooking for 4-5 persons and 7-8 
persons respectively and not in terms of their power levels). The Tara stove goes up to $3 \mathrm{~kW}(\mathrm{~T}-2)$. These were the only single-pan stoves available for detailed examination. On the whole, 7 stoves, Swosthee-1 kW-S-1 (I), Swosthee-2 kW-S-2, modified Swosthee-1.5 kW-MS-1.5, modified Swosthee-4 kW-MS-4, Priyagni-SP-S, Priyagni-M-P-M, and Tara (T-2) were examined in detail by the authors for their performance.

\section{Dependence on vessel size and shape}

During field testing, several houses in rural areas around Bangalore were visited. From the visits it appeared that vessels of a variety of sizes were in use. In a few cases, it was suspected that the use of small vessels-some flat-bottomed and some curved-resulted in higher wood consumption for cooking. This was inferred from the way the flame was enveloping the vessel as happens when cooking with open flames. Therefore it became important to determine the fraction of rural households using a given type of vessel for a particular cooking activity. Fortunately, during a diffusion programme of the ASTRA-Ole, the KSCST (Karnataka State Council for Science \& Technology) had acquired information regarding the pattern of vessel usage, and in fact systematic analysis was available, extracts from which are presented in table 9 (private communication-KSCST). These show that the majority of vessels used are in the range of $0.2 \mathrm{~m}$ diameter and above; smaller vessels are generally used for boiling milk, heating water for preparing coffee/tea and the like, while the major task of cooking food is done on flat-bottomed vessels of larger than $0.2 \mathrm{~m}$ diameter. Also, most vessels used are of aluminium or copper both of which are excellent conductors of heat. Therefore it became important to examine how the efficiency of a stove varies as a function of vessel size during both water-boiling and cooking tests.

\section{Further experiments with efficiency}

Table 10 indicates various features of vessels considered. Before efficiency tests were conducted, each stove was rated for its nominal, peak and low power. Occurrence of sooting at high power and smoking at low power were also recorded. Some

Table 9. The size of the pans used in houses.

\begin{tabular}{lcc}
\hline $\begin{array}{l}\text { Range of vessel } \\
\text { diameters } \\
(\mathrm{m})\end{array}$ & $\begin{array}{c}\text { Percentage of the } \\
\text { total number } \\
\text { surveyed }\end{array}$ & $\begin{array}{c}\text { Present } \\
\text { nomenclature }\end{array}$ \\
\hline $0 \cdot 15-0 \cdot 17$ & 9 & $\mathrm{G}$ \\
$0 \cdot 17-0 \cdot 19$ & 10 & $\mathrm{G}, \mathrm{F}$ \\
$0 \cdot 19-0 \cdot 21$ & 28 & $\mathrm{~F}, \mathrm{E}$ \\
$0 \cdot 21-0 \cdot 23$ & 23 & $\mathrm{E}$ \\
$0.23-0.25$ & 22 & $\mathrm{C}$ \\
0.25 and larger & 7 & $\mathrm{~B}, \mathrm{~A}$ \\
\hline
\end{tabular}

These results are from a random sample of seventy houses and characterisation of about two hundred vessels (private communication, KSCST). 
Table 10. Water-boiling efficiency of various stoves at nominal power (accuracy $= \pm 2 \%$ ).

\begin{tabular}{lccccccc}
\hline & & \multicolumn{7}{c}{ Eficiency (\%) } \\
\cline { 3 - 8 } Vessel & $\begin{array}{c}\text { Diameter } \\
(\mathrm{m})\end{array}$ & S-1 (I) & MS-1·5 & P-S & P-M & T-2 & MS-4 \\
\hline A & $0 \cdot 310$ & 42 & 43 & 34 & 30 & $-{ }^{+}$ & 40 \\
B & $0 \cdot 265$ & 40 & 38 & 30 & 26 & - & 36 \\
C & $0 \cdot 245$ & 36 & 35 & 30 & 28 & 30 & 34 \\
D & $0 \cdot 16^{++}$ & 28 & 30 & - & - & - & - \\
E & $0 \cdot 210$ & 29 & 27 & 28 & 26 & 28 & 22 \\
& & $36 / \mathrm{s}^{*}$ & $34 / \mathrm{s}$ & & & & $30 / \mathrm{s}$ \\
F & $0 \cdot 185$ & 30 & 25 & 27 & 24 & 26 & 19 \\
& & $35 / \mathrm{s}$ & $33 / \mathrm{s}$ & & & & $27 / \mathrm{s}$ \\
G & $0 \cdot 17$ & 27 & 22 & 23 & - & 22 & 17 \\
& & $33 / \mathrm{s}$ & $31 / \mathrm{s}$ & & & & $26 / \mathrm{s}$ \\
\hline
\end{tabular}

+Vessels cannot be used because of design restrictions.

${ }^{++}$Refers to a round-bottomed vessel. Largest diameter is reported.

*s-Implies tests with shield around the vessel.

features were recorded only qualitatively with 'plus' and 'minus' signs. A minus sign indicates lack of sooting or smoking, ' + ' indicates that it was moderate and ' ++ ' indicates that it was significant. $\mathrm{A}^{\prime}+++{ }^{\prime}$ ' sign is used when sooting/smoking was profuse.

The severity of the extent of sooting/smoking was roughly as per the order indicated in table 11 . The turn-down ratios (the ratio of the highest power output to

Table 11. Operating characteristics of stoves.

\begin{tabular}{|c|c|c|c|c|}
\hline & $\begin{array}{c}\text { Power } \\
\text { kW }\end{array}$ & $\begin{array}{l}\text { Turn-down } \\
\text { ratio }\end{array}$ & Sooting & Smoke \\
\hline $1 \mathrm{~kW}$ Swosthee S-1 (I) & $\begin{array}{ll}1.4 & \mathrm{H} \\
1.0 & \mathrm{~N} \\
0.27 \mathrm{~L}\end{array}$ & $5 \cdot 1$ & $\begin{array}{l}+ \\
- \\
-\end{array}$ & $\begin{array}{l}- \\
-\end{array}$ \\
\hline Modified Swosthee (MS-1.5) & $\begin{array}{ll}2.0 & \mathrm{H} \\
1.6 \mathrm{~N} & \mathrm{~N} \\
0.44 \mathrm{~L}\end{array}$ & $4 \cdot 5$ & $\begin{array}{c}++ \\
+ \\
-\end{array}$ & $\begin{array}{c}- \\
- \\
+ \\
\text { (Occasional) }\end{array}$ \\
\hline Priyagni (P-S) & $\begin{array}{ll}2.5 & \mathrm{H} \\
1.8 & \mathrm{~N} \\
0.6 & \mathrm{~L}\end{array}$ & $4 \cdot 1$ & $\begin{array}{l}+++ \\
++ \\
-\end{array}$ & $\begin{array}{c}- \\
+ \\
+ \\
\text { (Occasional) }\end{array}$ \\
\hline Tara (T-2) & $\begin{array}{ll}2.6 & \mathrm{H} \\
2.0 & \mathrm{~N} \\
0.65 \mathrm{~L}\end{array}$ & $4 \cdot 0$ & $\begin{array}{c}++ \\
++ \\
-\end{array}$ & $\begin{array}{l}- \\
+ \\
++\end{array}$ \\
\hline Priyagni (P-M) & $\begin{array}{ll}3.5 & \mathrm{H} \\
2.2 & \mathrm{~N} \\
0.8 & \mathrm{~L}\end{array}$ & $4 \cdot 3$ & $\begin{array}{c}++ \\
++ \\
-\end{array}$ & $\begin{array}{l}- \\
+ \\
++\end{array}$ \\
\hline
\end{tabular}

$\mathrm{H}=$ High; $\mathbf{N}=$ Nominal; $\mathrm{L}=$ Low.

+ Present in amounts varying with number of pluses.

- Absent. 
the lowest power output) of most of the stoves were between 4 and 5 and were satisfactory. This compares favourably with the measurements of Krishna Prasad et al (1983); of the 11 kerosene stoves tested by him only two had turn-down ratios larger than 5 , these values were 5.5 and 6.7 . While the use of a single stick posed problems of combustion in MS-1.5, it was almost impossible to operate with only one stick in the case of Priyagni and Tara. Co-operative combustion between sticks was vital for the operation of Priyagni and Tara, was desirable for modified Swosthee and was unimportant for Swosthee (the environment in Swosthee was so hot that volatilising and combusting even a single stick posed no problem; further, grateless combustion also helped by not having any cold air in the combustion chamber which could have drawn the local mixture away from the inflammability limit).

Results of water-boiling tests are shown in table 10 and figure 11. Experiments in all cases were run for durations of 45 to $60 \mathrm{~min}$.

In the case of smaller vessels, whose volumetric capacities are lower, a single water-boiling experiment would be complete in 20-25 min. In such cases the experiment was repeated over two runs to approximate a cooking sequence of one hour.

The efficiency dropped with decrease in the size of the vessel from $43 \%$ to about $27 \%$ with about $60 \%$ decrease in the diameter of the vessel. In order to enhance the

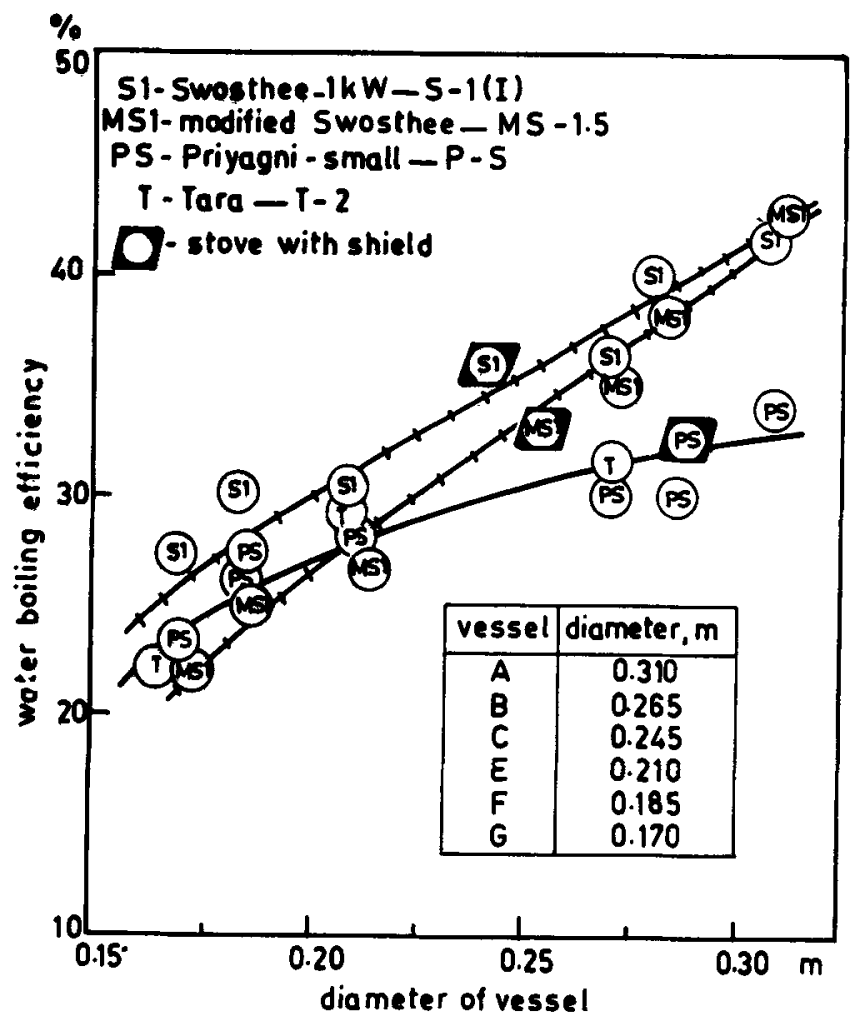

Figure 11. Variation of water-boiling efficiency with the diameter of the vessel used for cooking. 
efficiency for lower vessel size, an external cylindrical shield was separately kept around the vessel so that the hot gases passed through the annular passage of $0.005 \mathrm{~m}$ spacing. The enhancement in efficiency was indeed significant -5 to $10 \%$ for vessels $E, F$ and $G$. The shields were simply cylindrical rings of mild steel sheets.

The performance of MS-1.5 was comparable to that of Swosthee (S-1 (I)) except at lower vessel sizes where the improvement due to the use of the shield brings the performance back to that of S-2. The performances of P-S and P-M were interesting in that they did not vary with vessel size as much as in the case of MS-1.5 and S-1 (I). P-M cannot be used for vessel sizes smaller than 0.18 m and even P-S can be used only with difficulty with vessel $G$ of diameter $0.17 \mathrm{~m}$ because of the arrangemen $i$ they have to support vessels. They however can be easily modified to include vessels $F$ and $G$. Stove Tara has an outer shield into which the vessel has to be lowered and therefore vessels with diameter more than $0.25 \mathrm{~m}$ cannot be used. It performed marginally better than P-S. MS-4 has a performance slightly inferior to MS-1.5 but better than P-M, particularly when smaller sized vessels are used with the shield. It must be noted that the designs of P-S and P-M do not permit the possibility of using shields and so the effects could not be evaluated.

A particular feature of Swosthee is that its efficiency falls rather steeply if it is used much beyond the peak power level. At $2 \mathrm{~kW}$ which is twice the nominal and 1.4 times the peak, the efficiency drops down to $17 \%$.

Cooking tests were conducted on most of the stoves and very extensively on MS1.5 and P-S with vessels of a variety of sizes. Table 12 shows the cooking results for MS-1.5 and P-S. The cooking time has an inverse relationship with power but the difference is not very significant. The average reduction in SFC, $\mathrm{kg}$ of fuel required to cook $1 \mathrm{~kg}$ of food, using MS-1.5 is about $15 \%$ as compared to that with P-S. The results of cooking tests with smaller vessels are shown in table 13. It appears that MS- 1.5 is inferior to P-S by $10-15 \%$ in terms of SFC when cooking is done without the shield; but with the shield, the SFC gain is about $15 \%$ which indicates the importance of the shield while using vessels of smaller sizes. Use of larger flatbottomed vessels, even of smaller capacities, would enhance the cooking efficiency significantly.

Table 12. Results of cooking tests.

Food cooked: $0.75 \mathrm{~kg}$ rice $+1.9 \mathrm{~kg}$ water, vessel $\mathrm{B},(0.27 \mathrm{~m}$ dia, $0.12 \mathrm{~m}$ high).

\begin{tabular}{lcccc}
\hline Wtove & $\begin{array}{c}\text { Water-boiling } \\
\text { efficiency } \\
(\%)\end{array}$ & $\begin{array}{c}\text { Time for } \\
\text { cooking } \\
(\mathrm{s})\end{array}$ & $\begin{array}{c}\text { Power } \\
(\mathrm{kW})\end{array}$ & $\begin{array}{c}\text { SFC } \\
(\mathrm{kg} / \mathrm{kg} \\
\text { cooked food })\end{array}$ \\
\hline MS-1.5 & $42 \cdot 0$ & 1260 & 1.76 & 0.073 \\
MS-1.5 & $42 \cdot 3$ & 1800 & 1.57 & $0-065$ \\
MS-1.5 & $42 \cdot 0$ & 1920 & 1.31 & 0.061 \\
MS-1.5 & $41 \cdot 7$ & 1800 & 1.32 & 0.062 \\
MS-1.5 & 42.6 & 1800 & 1.65 & 0.069 \\
P-S & 28.0 & 1560 & 2.25 & 0.081 \\
P-S & 28.0 & 1500 & 2.22 & 0.077 \\
P-S & 28.0 & 1740 & 1.80 & 0.074 \\
P-M & 26.0 & 1620 & 2.50 & 0.092 \\
P-M & 26.2 & 1620 & 2.40 & 0.092 \\
\hline
\end{tabular}


Table 13. Results of cooking tests.

Amount cooked: $0.300 \mathrm{~kg}$ rice $+0.750 \mathrm{~kg}$ water.

\begin{tabular}{|c|c|c|c|c|c|c|}
\hline \multirow[b]{3}{*}{ Vessel } & \multicolumn{4}{|c|}{ MS-1.5 } & & \\
\hline & \multicolumn{2}{|c|}{ Without shield } & \multicolumn{2}{|c|}{ With shield } & \multicolumn{2}{|r|}{ P-S } \\
\hline & $\begin{array}{c}\text { Power } \\
(\mathrm{kW})\end{array}$ & $\begin{array}{c}\text { SFC } \\
(\mathrm{kg} / \mathrm{kg} \text { cooked } \\
\text { food })\end{array}$ & $\begin{array}{c}\text { Power } \\
(\mathrm{kW})\end{array}$ & $\begin{array}{c}\text { SFC } \\
(\mathrm{kg} / \mathrm{kg} \text { cooked } \\
\text { food })\end{array}$ & $\begin{array}{c}\text { Power } \\
(k W)\end{array}$ & $\begin{array}{c}\text { SFC } \\
(\mathrm{kg} / \mathrm{kg} \text { cooked } \\
\text { food })\end{array}$ \\
\hline E & $1 \cdot 3$ & 0.120 & $1 \cdot 3$ & 0.094 & 1.8 & $0 \cdot 110$ \\
\hline $\mathrm{F}$ & $1 \cdot 3$ & 0.118 & $1 \cdot 2$ & 0.093 & 1.6 & 0.107 \\
\hline$G$ & $1 \cdot 4$ & 0.130 & $1 \cdot 4$ & 0.094 & 1.4 & $0 \cdot 108$ \\
\hline
\end{tabular}

Average of 4 tests in each case with power at nominal $\pm 0.2 \mathrm{~kW}$ and $\mathrm{SFC}$ at values indicated $\pm 0.004 \mathrm{~kg} / \mathrm{kg}$ cooked food.

Decrease in cooking efficiency when smaller amounts are cooked in a larger vessel were determined. The SFC drops from about 0.09 to about 0.057. The difference in SFC while cooking on P-S and MS-1.5 is very significant. The gain in SFC with MS-1.5 in comparison to P-S is $8 \%$ at the lowest and $18 \%$ (see figure 12) at the best. The relationship between SFC and water-boiling efficiency is such that SFC drops with increase in efficiency rather nonlinearly, dropping sharply beyond $30 \%$ efficiency and going to as low as 0.057 at efficiencies close to $40 \%$ (see figure 13).

\section{An overview and comparison between stoves}

The primary purpose of designing stoves is to obtain high efficiency with smokeless and sootless combustion at affordable stove cost. The designs should be user-

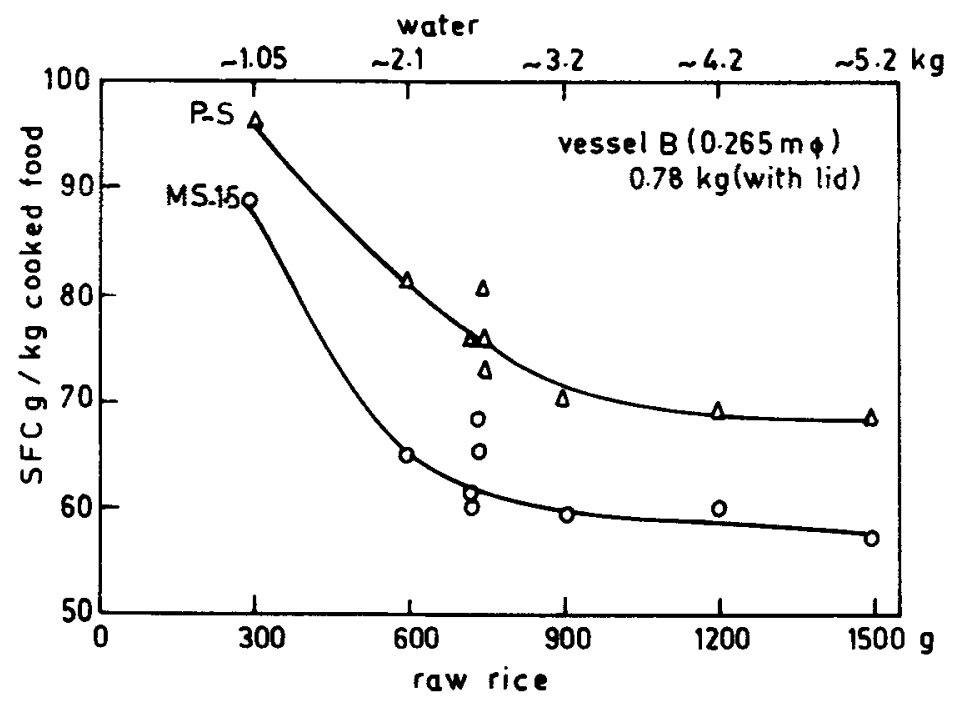

Figure 12. Variation of SFC with the quantity of rice cooked. 




Figure 13. Correlation between SFC and water-boiling efficiency obtained with MS-1.5 and vessel $\mathrm{B}$ by varying the quantities of water being heated and rice being cooked.

friendly, because only then will they survive the test of time. The authors' own appreciation of what constitutes user-friendliness has changed over a period of time, more significantly during the field tests. It became clear that high efficiency or low SFC must be incorporated into new designs but cannot be projected as their primary feature because a large number of users seem to care less about it than about a few other features. This is partly due to the fact that a large section of the rural population does not buy firewood, but collects it from areas around. The value attached to human labour in collecting firewood or fuel for cooking, however difficult that may be, is not the same as the value attached for expenditure in terms of hard cash. This particular feature poses a threat to any drive towards conservation of fuel reserves and hence alternate means of attaching explicit financial values to fuel obtained from any source seems desirable.

The desirable features of new stoves are smokeless operation and an ability to cook rapidly, requiring as little attention as possible. Further user-friendliness in operation is achieved by letting the users see the fire to judge the power. Even those users who have had conventional stoves with chimneys could tolerate reasonable amounts of smoke from a chimneyless stove. (Stoves with chimneys do not always assure smokeless operation in the kitchen. A survey conducted by ASTRA 1987a, indicated that of the 273 families which were using the ASTRA-Ole in the area of survey, $18 \%$ complained of smoke in the kitchen.) Thus the designer has less motivation to incorporate smokeless operation while designing stoves without chimneys.

An important aspect from the point of view of the user is that the cost of any stove cannot be exorbitant. At present in India an acceptable price for a metal stove is about Rs 50 to 75. Any higher cost calls for some justification, at least with regard to aesthetics and the get-up of the stove, and would be meaningful only in kitchens in urban areas.

It is in this scenario that one can compare the various stoves discussed earlier. The $1 \mathrm{~kW}$ Swosthee, $\mathrm{S}-1$ (I), is an efficient stove in terms of its SFC. Its problems as stated by the users are (a) its fuel-feed port is small, (b) operation needs continuous 
attention, (c) flame is not visible during operation, and (d) takes longer duration for cooking as compared to traditional stoves.

Points (a), (b) and (d) are related to the power level and any increase of power level would call for increased port size and possible reduction in attention demanded due to larger volume of fuel that could be charged at a time. During operation neither flame nor smoke is seen at power levels of $1 \mathrm{~kW}$ or less which was considered a desirable feature since it keeps the pollution level low as compared to most conventional stoves which either smoke extensively or show up a large visible fire making it difficult to work near the stove, particularly during summer. Since the users views proved different, an alternate design MS-1.5, was conceived-having higher power to meet cooking requirements in one hour, with the possibility of lower cost because of its relatively simple design. The size of the fuel loading port is larger and the presence of a perforated sheet around the combustion zone makes the flame visible to the user during operation. While the cost of fabrication of S-1 turned out to be Rs 90, the cost of MS-1.5 is expected to be no more than Rs 50-60. In fact one fabricator was marketing MS-1.5 and MS-4 in Bangalore at Rs 65 and 100 respectively in 1987 . The cost includes Rs 15 paid as commission to the dealers and he has sold about 450 stoves altogether. This cost can be compared with the cost of Rs 101 and 73, depending on chimney materials used, of the ASTRA-Ole which has been disseminated to about 0.15 million households (Baldwin et al 1985); MS-1.5 seems to have corrected the drawbacks of S-1 in terms of those features which are of concern to users.

In summary, it appears that MS-1.5 and MS-4 are two of the best high efficiency user-friendly designs amongst the currently available stoves at least in India. Use of these stoves in comparison to Priyagni-S and Priyagni-M leads to conservation of fuel to the extent of $10-20 \%$ depending on features like vessel size and cooking duration. In comparison, the ASTRA-Ole and traditional stoves consume $50 \%$ to $185 \%$ more fuel respectively. In addition, pollution levels are expected to be lower particularly at higher power levels.

Regarding the possible impact of fuel conservation due to the use of Swosthee and Modified Swosthee the values of SFC obtained with these stoves are compared with those available with other stoves in table 14. While the lowest SFC figures obtained with each model in the laboratory using specified cooking sequences are comparable for Swosthee, Modified Swosthee, Tamil Nadu stove and the ASTRAOle, the authors' models exhibit relatively large advantages over the field measurements of SFC of the ASTRA-Ole and traditional stoves.

\section{Concluding remarks}

The present report has examined the various principles involved in the design of single-pan wood stoves. Based on an assessment of the cooking needs of families in semi-urban and rural households, specifications for an efficient stove have been drawn up. They indicate that a stove of $1.5-3 \mathrm{~kW}$ capacity at an efficiency of about $40 \%$ would be satisfactory for meeting average cooking needs; the elimination of smoke should be an important element in the design.

Two new designs called Swosthee and modified Swosthee have been evolved based on different concepts. In Swosthee, the emphasis has been to mix the pyrolysed fuel and air well, create a hot environment and provide enough residence 
Table 14. Comparison of SFC of different stoves.

\begin{tabular}{|c|c|c|}
\hline Stove make & Details of measurement & $\begin{array}{l}\mathrm{SFC}(\mathrm{kg} \text { of wood } / \mathrm{kg} \\
\text { of cooked food) }\end{array}$ \\
\hline $\begin{array}{l}\text { Swosthee, S-1 (I) } \\
\text { Modified Swosthee } \\
\text { MS-1.5 }\end{array}$ & $\begin{array}{l}\text { Authors' measurements } \\
\text { with only rice } \\
\text { with an entire meal }\end{array}$ & $\begin{array}{c}0.060-0.090 \\
0.140 \pm 0.005\end{array}$ \\
\hline $\begin{array}{l}\text { Priyagni P-S, P-M } \\
\text { Tamil Nadu }\end{array}$ & $\begin{array}{l}\text { Authors' measurements } \\
\text { Lab experiments with only rice }\end{array}$ & $\begin{array}{l}0.075-0 \cdot 110 \\
0.058-0.082^{+}\end{array}$ \\
\hline ASTRA-Ole* & $\begin{array}{l}\text { In the laboratory } \\
\text { In lab using a specific two-step cooking } \\
\text { procedure } \\
\text { In the field }\end{array}$ & $\begin{array}{l}0.150^{* * * *} \\
(0-060-0 \cdot 080)^{*} \\
.209 \pm 0.058^{* *}\end{array}$ \\
\hline Traditional stove* & $\begin{array}{l}\text { From a sample of } 20 \text { stoves around } \\
\text { Ungra village near Bangalore }\end{array}$ & $\cdot 400 \pm 0 \cdot 105^{* *}$ \\
\hline
\end{tabular}

\footnotetext{
${ }^{+}$Estimated from Sulilatu \& Krist-Spit (1985)

*As quoted in Krishna Prasad (1985a)

**From ASTRA (1987a).
}

time for combustion to be completed. In modified-Swosthee, the attempt is to create a small enough combustion zone to limit the burn rate and allow the diffusion flame to dominate the combustion process: The consistently higher temperature of the diffusion flame seems to compensate for the lack of 'premixedness'. A perforated cylinder around the flame restricts the entry of air mostly to the fuel port and thus aids in limiting the air to fuel ratio.

Both the stoves along with the ones available in the market-like Priyagni and Tara-have been tested for water boiling efficiency and specific fuel consumption for a specified cooking sequence. The results indicate that the modified Swosthee has an SFC of $0.060-0.090 \mathrm{~kg}$ of wood $/ \mathrm{kg}$ of cooked rice, as compared to other singlepan designs which have $10-20 \%$ higher values at comparable power, vessel shapes and size.

One of the important results to be taken note of by vessel manufacturers and users is that vessels with a larger diameter to volume ratio lead to better fuel efficiencies.

The modified Swosthee is comparable in cost to currently available metal stove designs; the possibility of reducing the cost by making clay stoves (pottery) exists and is being explored. It should even be possible to use pottery to make the stove artistically elegant to help it attract users.

From an examination of various factors that affect the performance of woodburning cook stoves, it appears to the authors that the possibility of improving efficiencies beyond $45-50 \%$ at relatively low cost seems rather remote at piesent.

The authors wish to thank Professor R Narasimha and Dr Sam Baldwin for their valuable comments on the manuscript. The results presented here are the outcome of the projects on "Wood Stoves" financed and administered by the Karnataka State Council for Science and Technology, Indian Institute of Science, Bangalore. The authors are grateful to the KSCST for the support provided. 


\section{References}

Agarwal A L, Dave R M, Smith K R 1983 ASSET 5: 18

Anon 1984 Diffusion of biomass energy technologies in developing countries (2nd edn) (Washington, DC; Natl. Acad. Press)

ASTRA 1987a Development, field testing and impact of wood stoves, Final Report of the DST Project, ASTRA, Indian Institute of Science, Bangalore

ASTRA 1987b Evaluation of the ASTRA stove programme, ASTRA, Indian Institute of Science, Bangalore

Baldwin S F 1986 Biomass stoves: Engineering design, development and dissemination, Volunteers in Technical Assistance, Center for Energy and Environmental Studies, Princeton University, Princeton NJ

Baldwin S, Geller H, Dutt G, Ravindranath N H 1985 Ambio 14: 280-287

Bhatt M S 1982 Proc. Indian Acad. Sci. (Eng. Sci.) 5: 327-342

Bussmann P J T, Visser P, Krishna Prasad K 1983 Proc. Indian Acad. Sci. (Eng. Sci.) 6: 1-34

Bussmann P J T 1984 Field studies; Wood-burning cookstoves, Report, Dept. Appl. Phys., Eindhoven Univ. Technol., Eindhoven

Bussman P J T 1988 Wood stoves: theory and application in developing countries, Ph.D thesis, Eindhoven Univ. Technol., Eindhoven

Clans J, Sulilatu W F 1983 Proc. Indian Acad. Sci. (Eng. Sci.) 5: 343-359

De Lepeleire G, Krishna Prasad K, Verhaart P, Visser P (eds) 1981 A wood stove compendium (Eindhoven: Univ. Technol.)

De Lepeleire G, Christiaens M 1983 Proc. Indian Acad. Sci. (Eng. Sci.) 6: 35-46

Emmons H W, Atreya A 1982 Proc. Indian Acad. Sci. (Eng. Sci.) 5: 259-268

Foley G, Moss P 1983 Stoves in developing countries, Earthscan Technical Report No. 2, London

Geller H S 1982 Proc. Indian Acad. Sci. (Eng. Sci.) 5: 373-393

Gill J 1983 Proc. Indian Acad. Sci. (Eng. Sci.) 6: 79-94

Gupta C L, Rao U K, Prema U 1982 Proc. Indian Acad. Sci. (Eng. Sci.) 5: 395-408

Krishna Prasad K 1985a Towards Mass Production of Wood-Burning Stoves, prepared for the UNiDO stove meeting at Vienna, Austria, March

Krishna Prasad K 1985b in From design to cooking, Report, Dept. Appl. Phys., Eindhoven Univ. Technol., Eindhoven

Krishna Prasad K, Sangen E (eds) 1983 Technical aspects of Wood-Burning Stoves, Dept. Appl. Phys., Eindhoven Univ. Technol., Eindhoven

Krishna Prasad K, Sangen E, Sielcken M, Visser P 1983 Test results on kerosene and other stoves, Report, Dept. Appl. Phys., Eindhoven Univ. Technol., Eindhoven

Krishna Prasad K, Sangen E, Visser P 1985 Adv. Heat Transfer 17: 159-317

Krishna Prasad K, Verhaart P (eds) 1983 Wood heat for cooking (Bangalore: Indian Acad. Sci.)

Krist-Spit C E, Van der Heeden D J (eds) 1985 From design to cooking, Report, Dept. Appl. Phys., Eindhoven Univ. Technol., Eindhoven

Lokras S S, Sudhakar Babu D S, Bhogle S, Jagadish K S, Kumar R 1983 Development of an improved three-pan cookstove Changing villages, New Delhi, 5 (5), Sept-Oct.

Manibog F R 1984 Improved cooking stoves in developing countries: Problems and opportunities, Annu. Rev. Energy, Inc., USA

Micuta W 1985 Modern stoves for all (revised edn) (London: Intermediate Technol. Publ. \& the Bellerire Foundation)

Mukunda H S, Shrinivasa U 1985 Single-pan wood stove of high efficiency, Report, ASTRA, Indian Inst. Sci., Bangalore

Mukunda H S, Shrinivasa U, Dasappa S, Sunil Kumar S B 1986 Development of single-pan wood stoves of high efficiency, Report, ASTRA, Indian Inst. Sci., Bangalore

Rapa Bulletin 1986 Development of efficient wood-burning stoves in India, Rural Energy Rapa Bulletin No. 1, FAO, Bangkok

Segeler C G (ed.) 1966 Gas engineers hand book: Fuel gas engineering practices (New York: Industrial Press)

Shailaja R, Ravindranath N H 1985 Dissemination and evaluation of the ASTRA stove in Ungra region, Proc. ASTRA Seminar, Indian Institute of Science, Bangalore

Sittig M 1974 Pollution detection and monitoring handbook (New York: Noyes Data Corporation)

Sulilatu W F 1985 in From design to cooking, (eds) C E Krist-Spit, D J Van der Heeden, Report, Dept. Appl. Phys., Eindhoven Univ. Technol., Eindhoven 
Sulilatu W F, Krist-Spit C E 1985 in From design to cooking, (eds) C E Krist-Spit, D J Van der Heeden, Report, Dept. Appl. Phys., Eindhoven Univ. Technol., Eindhoven

Van Gelder A, Hosier R, Van der Donk W 1983 Proc. Indian Acad. Sci. (Eng. Sci.) 6: 59-78

Van der Heeden D J, Sulilatu W F, Krist-Spit C E 1983 in Technical aspects of wood-burning cookstoves, (eds) Krishna Prasad, E Sangen, Dept. Appl. Phys., Eindhoven Univ. Technol., Eindhoven

Verhaart P 1981 in $A$ wood stove compendium (eds) G De Lepeleire, K Krishna Prasad, P Verhaart, $P$ Visser (Eindhoven: Eindhoven Univ. Technol.).

Verhaart P 1982 Proc. Indian Acad. Sci. (Eng. Sci.) 5: 287-326

Zaror C A, Pyle D L 1982 Proc. Indian Acad. Sci. (Eng. Sci.) 5: 269-285 